\title{
Axial Developments of Interfacial Area and Void Concentration Profiles in Subcooled Boiling Flow of Water
}

\author{
Tae-Ho Lee ${ }^{a^{*}}$, Rong Situ ${ }^{b}$, Takashi Hibiki ${ }^{c}$, Hyun-Sik Park ${ }^{d}$, Mamoru Ishii ${ }^{c}$ and Michitsugu Mori ${ }^{\text {e }}$ \\ a Fluid System Engineering Division, Korea Atomic Energy Research Institute, (150-1 Deokjin-Dong), \\ 1045 Daedeokdaero, Yuseong, Daejeon 305-353, Korea \\ b School of Aerospace, Mechanical, and Manufacturing Engineering, RMIT University, Plenty Road, \\ Bundoora, Victoria 3083, Australia \\ c School of Nuclear Engineering, Purdue University, 400 Central Drive, West Lafayette, IN \\ 47907-2017, USA \\ d Thermal Hydraulics Safety Research Department, Korea Atomic Energy Research Institute, (150-1 \\ Deokjin-Dong), 1045 Daedeokdaero, Yuseong, Daejeon 305-353, Korea \\ e R\&D Center, Tokyo Electric Power Company, 4-1 Egasaki, Tsurumi, Yokohama, Kanagawa \\ 230-8510, Japan
}

* Corresponding author: Tel: +82-42-868-8975, Fax: +82-42-861-7697, Email: thlee@kaeri.re.kr

\begin{abstract}
Axial developments of the local void fraction, interfacial area concentration and bubble Sauter mean diameter were measured in subcooled boiling flow of water in a vertical internally heated annulus using the double-sensor conductivity probe technique. Measurements were performed under varying conditions of heat flux, inlet liquid velocity and inlet liquid temperature. A total of 10 data sets were acquired. Based on these measurements with the previous data obtained in the present test loop, the influence of flow condition on the profiles of local two-phase flow parameters was discussed. The measured average void fraction and interfacial area concentration were compared with the predictions by existing correlations for drift-flux parameters and interfacial area concentration. Also, the recently proposed bubble layer thickness model in subcooled boiling was evaluated for the measurement data.
\end{abstract}

Key Words: Subcooled boiling flow, internally heated annulus, Void fraction, Interfacial area concentration, Drift-flux parameters, Bubble-layer thickness
Nomenclature
$a_{i} \quad$ interfacial area concentration
$C_{o} \quad$ distribution parameter
$D_{b} \quad$ bubble diameter
$D_{H} \quad$ hydraulic equivalent diameter 


\begin{tabular}{|c|c|}
\hline$D_{\text {rod }}$ & heater diameter \\
\hline$D_{s m}$ & Sauter mean diameter \\
\hline$G$ & mass flux \\
\hline$g$ & gravitational acceleration \\
\hline$j$ & mixture volumetric flux \\
\hline$j_{g}$ & superficial gas velocity \\
\hline$j_{l}$ & superficial liquid velocity \\
\hline$N_{B o}$ & boiling number \\
\hline$N_{J a}$ & Jacob number \\
\hline$N_{R e}$ & Reynolds number \\
\hline$N_{\text {sub }}$ & subcooling number \\
\hline$N_{W e}$ & Weber number \\
\hline$N_{\mathrm{Zu}}$ & Zuber number \\
\hline$P$ & pressure \\
\hline$q^{\prime \prime}$ & heat flux \\
\hline$R$ & inner radius of outer round tube \\
\hline$R_{o}$ & radius of inner heater rod \\
\hline$r$ & radial coordinate \\
\hline$T$ & temperature \\
\hline$V_{g j}$ & weighted mean drift velocity \\
\hline$v_{f i}$ & inlet liquid velocity \\
\hline$v_{g}$ & gas phase velocity \\
\hline$v_{r}$ & relative velocity \\
\hline$x_{e q}$ & thermal equilibrium quality \\
\hline$z$ & axial coordinate \\
\hline \multicolumn{2}{|c|}{ Greek symbols } \\
\hline$\alpha$ & void fraction \\
\hline$\Delta T_{\text {sub }}$ & inlet subcooling \\
\hline$\Delta P$ & pressure difference \\
\hline$\mu$ & dynamic viscosity \\
\hline$v$ & kinematic viscosity \\
\hline$\rho$ & density \\
\hline$\sigma$ & surface tension \\
\hline \multicolumn{2}{|c|}{ Subscripts } \\
\hline crit & critical \\
\hline$F$ & friction \\
\hline$f$ & liquid phase \\
\hline
\end{tabular}




$\begin{array}{ll}f i & \text { fluid inlet } \\ g & \text { vapor phase } \\ h & \text { heating } \\ m & \text { mixture } \\ \text { in } & \text { inlet }\end{array}$

\section{Introduction}

Accurate predictions of void fraction and interfacial area concentration in subcooled boiling regime are essential for boiling water reactor (BWR) safety analysis. The void fraction affects the heat transfer rate in the reactor core, the stability and the core reactivity. Also, the interfacial area concentration takes a significant role in the estimation of heat transfer capability, and is one of the key parameters in the current nuclear reactor safety analysis codes such as RELAP5, TRAC, and CATHARE in which two-fluid model is employed. In such codes, the void fraction is solved as a dependent variable while the interfacial area concentration should be given as a constitutive relation. Currently, the interfacial area concentration is implemented as flow regime dependent empirical correlation in most safety analysis codes with two-fluid model [1]. This approach, however, does not mechanistically represent the changes in interfacial structure and may lead to the numerical oscillations in system behavior due to its static and flow regime dependent nature. Recently, the interfacial area transport equation has been introduced to improve the two-fluid model [2]. It can replace the traditional flow regime maps and regime transition criteria. Thus, the interfacial area transport equation is expected to contribute to a great improvement in the predictive capability of code in safety analysis.

In order to develop a reliable interfacial area transport equation applicable to subcooled boiling flow, fundamental experiments to obtain accurate data sets for the distributions of local two-phase flow parameters are indispensable because the related model development and its validation depend on the availability of quantitative information on the subcooled boiling flow field. Especially, in view of the importance to the interfacial area transport equation, accurate data sets on the local void fraction and interfacial area concentration are required in various channel geometries and flow conditions.

Over the past 20 years, extensive experimental studies on the local measurements of these parameters in two-phase flow have been carried out. However, most of the studies have been restricted to an adiabatic bubbly flow due to the practical importance in many engineering applications. In subcooled boiling flow, most of previous works have dealt understandably with the measurements of gross effects rather than local effects. The earliest experiment to attempt the measurement of local void fraction was by Delhaye et al. [3]. They developed a fast micro-thermocouple that could enable the detection of the vapor or liquid phase, and measured the local void fraction and temperatures of liquid and vapor in steam-water flow. The local void fraction was estimated from the probability density function of the temperature signals. Sekoguchi et al. [4] used the single-sensor conductivity probe to measure both radial and axial distributions of local void fraction in subcooled and low quality boiling flow of water through cylindrical tubes. Hasan et al. [5] measured radial profiles of void fraction in subcooled boiling of R-113 through a 
vertical annulus. The void fraction was measured by a cylindrical hot-film sensor. Roy et al. [6] measured the local void fraction and the bubble size in subcooled boiling flow of R-113 through a vertical annulus. The void faction was measured by optical fiber probe. The local interfacial area concentration was also estimated using the measured void fraction and bubble size. Zeitoun et al. [7] also measured the void fractions and mean bubble sizes at various axial locations in subcooled flow boiling. The bubble mean diameter which can be used to calculate interfacial area concentration was determined using high-speed photography, and the void fraction was measured by a single-beam gamma densitometer. Based on the measured data, they proposed a correlation for mean bubble diameter. Recently, Garnier et al. [8] performed the measurements of local two-phase flow parameters in R-12 flow boiling in a vertical channel. The void fraction and interfacial area concentration were measured by an optical probe. Also, Lee et al. [9] measured the radial profiles of local void fraction and velocities of both phases in subcooled boiling flow of water in a vertical concentric annulus with a heated inner tube. A double-sensor conductivity probe was used for the measurements of local gas phase parameters.

As stated above, most attempts have been made for the local measurement of void fraction, whereas a few works have been done for the interfacial area concentration measurement in spite of its crucial role in interfacial transfer mechanism. Moreover, the data on axial development of local two-phase flow parameters, which are very important to evaluate the interfacial area transport equation, are extremely limited so far. From this point of view, Thermal-hydraulics and Reactor Safety Laboratory in Purdue University have been performing extensive experiments to obtain accurate data sets on local two-phase flow parameters in subcooled boiling flow [10]. As a continuation of this activity, this study also aims to construct a reliable database to model the interfacial area transport mechanisms. Using the double-sensor conductivity probe method, the axial developments of local void fraction, interfacial area concentration and bubble Sauter mean diameter were measured in subcooled boiling flow of water in an internally-heated annulus which is scaled-down from a prototypic BWR. Combining these new data with the previous data [10] obtained in the present experimental facility, the influences of inlet liquid temperature, heat flux and inlet liquid velocity on the distribution of local flow parameters are discussed. In addition, the measured area-averaged void fraction and interfacial area concentration are compared with the predictions using existing correlations for drift-flux parameters and interfacial area concentration. Also, the recently proposed bubble layer thickness model [11] to formulate a one-dimensional interfacial area transport equation in subcooled boiling flow is tested to evaluate the applicability of the model.

\section{Experiments}

The test loop of present experiment has been designed to measure the relevant two-phase parameters necessary for developing constitutive models for the two-fluid model in subcooled boiling in BWR. It is a scaled-down loop from a prototypic BWR based on proper scaling criteria for geometric, hydrodynamic, and thermal similarities. Based on the scaling method by Situ et al. [12], the loop geometry and the thermal-hydraulic conditions in prototypic BWR and present scaled test loop were evaluated. The results of evaluation are presented in Table 1 where the subscript $\mathrm{R}$ denotes the ratio of the values for a 
present experiment to that for the prototype. In the table, the typical ranges of the similarity parameters covered in the present experiments are also tabulated. In the present test loop, the geometrical similarity is almost preserved, but the hydrodynamic and thermal similarities are not preserved due to the limited capability of the experimental equipment. However, since the geometrical similarity is preserved, the obtained data would provide the information on general basic flow characteristics in the channel of the BWR core.

A schematic of the test loop is shown in Fig. 1. The test loop mainly consists of a test section, a main tank and a circulating pump. The main tank holds the subcooled water, and has a cartridge heater and heat exchanger to control the inlet subcooling of test section. Distilled and degassed water from the main tank is pumped by a positive displacement pump, flows through a magnetic flow meter and is then divided into four separate lines. Each line runs to a fitting that is connected to the bottom of the test section. The test section contains a heated section where subcooled boiling occurs. The two-phase mixture at the test section outlet flows back through a separation tank to the main tank. The test section is a vertical concentric annulus that is formed by a transparent polycarbonate tube of $38.1 \mathrm{~mm}$ ID on the outside and a cartridge heater of $19.1 \mathrm{~mm}$ OD on the inside. The heater has an overall length of $2670 \mathrm{~mm}$ with a heated section of $1730 \mathrm{~mm}$ in length. The maximum power of the heater is $20 \mathrm{~kW}$ which corresponds to a maximum power of $0.193 \mathrm{MW} / \mathrm{m}^{2}$. The details of the experimental facility are described in the papers of Situ et al. $[10,12]$

The test section inlet temperature was measured by a thermistor probe with a sensor accuracy of $\pm 0.1{ }^{\circ} \mathrm{C}$. The volumetric flow rate entering the test section was measured by a magnetic flow meter. It has an accuracy of $\pm 1 \%$ full scale reading. The differential pressure between the inlet and outlet of the test section was measured by a differential pressure cell with an accuracy of $\pm 1 \%$ full scale reading. Heat flux was calculated from the power applied to the heater rod and the heated surface area, and the accuracy of it was estimated to be $\pm 1 \%$ of the rated heat flux.

The local two-phase parameters were measured by the double-sensor conductivity probe method. The details of the method are given by Hibiki et al. [13]. The measurement accuracies for void fraction and interfacial area concentration were estimated to be \pm 12.8 and \pm 6.95 , respectively. The measurements were taken at four axial locations of $z_{\mathrm{h}} / D_{\mathrm{H}}=31.3,52.6,68.7$, and 89.4. At each axial plane, the probe was traversed between $r /\left(R-R_{0}\right)$ of 0.05 and 0.90 to obtain the radial profiles of local flow parameters. Here, $z_{\mathrm{h}}$ and $D_{\mathrm{H}}$ are the axial distance from the beginning of heating section and the hydraulic diameter, respectively, and $r, R$, and $R_{0}$ are the radial location measured from the heater surface, the inner radius of outer tube, and the outer radius of heater rod, respectively.

Experiments were carried out at different levels of heat flux, inlet liquid velocity and inlet liquid temperature. The system pressure was maintained at atmospheric pressure. For the determination of experimental conditions, the experimental ranges of previous works on local measurements in subcooled boiling flow were examined. Table 2 summarizes the geometries and experimental conditions of those works including the present experiment. Also, the experimental ranges which have been covered by some experiments in Table 2 are represented in Fig. 2 where the data are shown in the plane of Jacob number at 
measuring position versus inlet liquid Reynolds number. The Jacob number at measuring position could not be calculated for some experiments in Table 2. Thus, only data in which Jacob number can be calculated are shown in the figure. Except for Garnier et al.'s work [8], test conditions of previous experiments were limited to low flow ranges compared with the condition of the prototypic BWR shown in Table 1. Also, it was found that most experimental works have not been performed in a system scaled to a prototypic BWR. The experiment of Garnier et al. [8] was intended to construct the database to be used for development of models which describe the boiling two-phase flow in pressurized water reactor (PWR) condition. From these considerations, the flow ranges of present experiment were extended to higher flow up to the inlet liquid Reynolds number of $1.27 \times 10^{5}$ in order to approach the typical condition in prototypic BWR within the capability of experimental equipment. A total of 10 data sets were acquired. The experimental conditions are given in Table 3 where $q^{\prime \prime}, T_{\text {in }}, v_{\mathrm{fi}}, \Delta P$ and $P_{\text {in }}$ are, respectively, the heat flux, the inlet liquid temperature, the inlet liquid velocity, the pressure difference between inlet and outlet, the inlet pressure. The experimental conditions of Situ et al.'s works [10] are also tabulated in the table. Those data will be used later in explaining the dependency of the distribution of local flow parameter on flow condition and evaluating the existing models.

\section{Results and Discussion}

\subsection{Void fraction}

Fig. 3 shows various profiles of the measured local void fraction, $\alpha$, in which some data sets by Situ et al.'s work [10] are also included. The graphs in the figure are organized to understand the effects of heat flux, inlet liquid temperature and inlet liquid velocity. In each graph, the radial profiles of local void fraction at a fixed axial location are represented. The graphs in the first, second, and third rows show the void fraction profiles measured at $z_{\mathrm{h}} / D_{\mathrm{H}}=52.6,68.7$ and 89.4, respectively. Thus, the axial development of the void profile can be seen by comparing the graphs in each row. The effect of heat flux on the void fraction profiles can be seen in the first column where the inlet liquid temperature and the inlet liquid velocity keep being constant. The second and third columns also show the dependencies of void profiles on the effects of inlet liquid temperature and inlet liquid velocity, respectively. In some component figures, some data sets are not shown, which means that no bubble was detected.

As shown in the first column of the figure, the void fraction not only increases in value, but also propagates along the radial direction as the heat flux increases. The radial locations of maximum void fraction move towards the outer wall as the flow develops along the axial direction. At lower axial plane of $z_{\mathrm{h}} / D_{\mathrm{H}}=52.6$ where the bulk subcooling is higher, the peak void fraction is observed near the heater surface explicitly due to a large number of bubbles generated from the nucleation sites on the heater surface. On the other hand, the location of maximum void fraction shifts to near-center of flow cross section at higher axial plane where the bulk subcooling is lower. In lower bulk subcooling condition, more bubbles can survive condensation while migrating toward the outer wall, which can causes large bubbles near the center of heater surface and outer wall by bubble coalescence. The degree of shifting by the decrease of bulk subcooling is shown to be more pronounced in low flow condition of $v_{\mathrm{fi}}=0.5 \mathrm{~m} / \mathrm{s}$ than in 
high flow condition of $v_{\mathrm{fi}}=1.0 \mathrm{~m} / \mathrm{s}$ because the axial increase of bulk temperature is larger for lower flow condition at same heat flux conditions. For the flow condition of of $q^{\prime \prime}=99.2 \mathrm{~kW} / \mathrm{m}^{2}, T_{\mathrm{in}}=98^{\circ} \mathrm{C}, v_{\mathrm{fi}}=0.5 \mathrm{~m} / \mathrm{s}$, the significant slug/cap bubbles were detected at $z_{\mathrm{h}} / D_{\mathrm{H}}=68.7$ and 89.4. This fact indicates that large slug/cap bubbles were formed by bubble coalescence. Since local void fraction is governed by bubble size and bubble number density, this means that the shift of peak void fraction toward outer wall is mainly due to the grown bubbles by bubble coalescence. The effects of inlet temperature and inlet velocity can also be seen in the second and third column, respectively. At lower inlet temperature and lower inlet velocity, the condensation rate is smaller and more bubbles survive. As such, the local void fraction grows with the decrease of inlet temperature and inlet velocity.

Fig. 4 shows the axial development of the area-averaged void fraction, $\langle\alpha\rangle$ as a function of the thermal equilibrium quality. The thermal equilibrium quality was calculated by the heat balance across the channel assuming no heat loss. The symbols in Fig. 4 indicate the experimental data, and the solid and broken lines denote the average void fractions calculated by the drift-flux model proposed by Ishii [19] and Hibiki et al. [11] which are listed in Table 4. As expected, the average void fraction increases along the flow direction due to the increase of nucleated bubbles on the heater surface, the decrease of condensation rate and the contribution from upstream region. The figure shows the typical average void fraction development in subcooled boiling flow where the low void fraction region is followed by the high void fraction region in which the average void fraction increases significantly. At about less than $10 \%$ of average void fraction, the rate of increase of average void fraction is small. Above $10 \%$, the average void fraction increases at a higher rate. For the flow conditions of $q^{\prime \prime}=99.2 \mathrm{~kW} / \mathrm{m}^{2}, T_{\mathrm{in}}=98.0^{\circ} \mathrm{C}, v_{\mathrm{fi}}=0.50 \mathrm{~m} / \mathrm{s}$ at $z_{\mathrm{h}} / D_{\mathrm{H}}=68.7$ and $89.4, q^{\prime \prime}=150.0 \mathrm{~kW} / \mathrm{m}^{2}, T_{\mathrm{in}}=99.0^{\circ} \mathrm{C}, v_{\mathrm{fi}}=1.00 \mathrm{~m} / \mathrm{s}$ at $z_{\mathrm{h}} / D_{\mathrm{H}}=89.4$, and $q^{\prime \prime}=193.0 \mathrm{~kW} / \mathrm{m}^{2}$, $T_{\mathrm{in}}=95.0{ }^{\circ} \mathrm{C}, v_{\mathrm{fi}}=1.00 \mathrm{~m} / \mathrm{s}$ at $z_{\mathrm{h}} / D_{\mathrm{H}}=89.4$, the average void fractions are too high for a subcooled boiling flow, and the corresponding thermal equilibrium qualities are high. These indicate that the boiling regimes are around the saturated bulk boiling flow for those flow conditions, and also significant slug/cap bubbles were observed. Especially, for the flow condition of $q^{\prime \prime}=99.2 \mathrm{~kW} / \mathrm{m}^{2}, T_{\mathrm{in}}=98{ }^{\circ} \mathrm{C}, v_{\mathrm{fi}}=0.5 \mathrm{~m} / \mathrm{s}$ at $z_{\mathrm{h}} / D_{\mathrm{H}}=$ 89.4 , the thermal equilibrium quality is 0 , which shows that the boiling regime reaches the saturated bulk boiling.

The average void fractions for data sets in Table 3 were compared with the predictions by several existing correlations which are based on the drift-flux model. The drift-flux model is expressed as follows [14].

$$
\frac{<j_{g}>}{<\alpha>}=C_{o}<j>+V_{g j}
$$

In Eq.(1), $j_{g}, j, C_{o}$ and $V_{g j}$ are the superficial gas velocity, the mixture volumetric flux, the distribution parameter and the void-fraction-weighted mean drift velocity, respectively, and $<>$ denotes the area-averaged value. The distribution parameter and the void-fraction-weighted mean drift velocity are defined as follows. 


$$
C_{o} \equiv \frac{\langle\alpha j\rangle}{<\alpha><j\rangle} \quad \text { and } \quad V_{g j} \equiv \frac{\left.<v_{g}-j\right\rangle}{<\alpha>}
$$

If the distribution parameter and the weighted mean drift velocity are given, the average void fraction can be calculated from Eq. (1) with measured superficial gas velocity and physical properties. In this study, six correlations for distribution parameter and weighted mean drift velocity $[11,14,15,16,17,18,19]$ were evaluated to examine the applicability of those models to subcooled boiling flow. They are listed in Table 4. Among them, the models of Kawanishi et al. [17] and Chexal et al. [18] were empirically developed based on the large database obtained in wide range of pressures, flows, and void fractions for steam-water flow. Their models were developed by fitting the average values from the global measurements. Hibiki et al. [11] have developed the distribution parameter considering the effect of channel geometry in boiling flow. Using the void fraction data obtained from local measurements in subcooled boiling flow, they proposed the distribution parameter applicable only to a boiling flow in an internally heated annulus.

Fig. 5 shows comparisons between the experimental data and the predictions by the various correlations in Table 4. In the figure, the distribution parameter is also compared because it is more dominant than the drift velocity in the determination of average void fraction. On the other hand, Table 5 shows the average deviation between the prediction and the data and the applicable geometry for each correlation. The prediction error for $\langle\alpha\rangle$ and $C_{o}$ are defined as

$$
\begin{aligned}
& \text { Prediction error for }\langle\alpha\rangle[\%] \equiv \frac{\left|\langle\alpha\rangle_{\text {mea. }}-\langle\alpha\rangle_{\text {cal. }}\right|}{\langle\alpha\rangle_{\text {mea. }}} \times 100 \\
& \text { Prediction error for } C_{o}[\%] \equiv \frac{\left|C_{o, \text { mea. }}-C_{o, \text { cal. }}\right|}{C_{o, \text { mea. }}} \times 100 .
\end{aligned}
$$

By averaging the prediction errors for whole data, the average deviation is obtained.

The experimental distribution parameter can be determined from Eq. (2), provided that the local void fraction and the local gas and liquid velocities are available. In this study, since no local liquid velocity data are available, the profile of the mixture volumetric flux in the estimation of distribution parameter using the measured local void fraction is approximated by

$$
j \equiv \frac{n+1}{n}<j>\left\{1-\left|1-\frac{2 r}{R-R_{o}}\right|^{n}\right\} .
$$

The exponent, $n$ is assumed to be 7 in this study [11].

In the processing of present experimental data, only the velocity signals from the spherical bubbles were collected. Because the slug/cap bubbles rise faster, the superficial gas velocity used in the calculation should be lower than the true gas velocity, which causes the under-estimation of average void fraction. Thus, the data sets which include significant slug/cap bubbles were excluded in the comparison.

As shown in Fig. 5, most of the correlations predict the present data well for average void fraction higher than about $1 \%$. However, for average void fraction lower than about $1 \%$, only the models of Hibiki et al. [11] and Ishii [19] could predict the measured data with a good accuracy. For Chexal et 
al.'s model [18] which satisfies the limiting condition on the distribution parameter at near-zero value of void fraction, the dependency of the distribution parameter on void fraction is too strong in low void fraction region and the distribution parameter is highly under-estimated leading to overestimation of void fraction. Also, for other models, the distribution parameters are over-estimated, which causes the underestimations of void fractions in low void fraction region. Generally, the distribution parameter depends on channel geometry. The effect of channel geometry on distribution parameter may be attributed to the difference in the position where void peaking appears between flow channels. For boiling in an internally heated annulus, the void peak exists near the wall of the inner heater rod, whereas for a round tube, the void peak appears near the wall of the tube. As indicated by Hibiki et al. [11], the effect is strong in low void fraction range. Using the data obtained from profile measurements of local void fraction in an internally heat annulus, they correlated the distribution parameter. On the other hand, the correlations by other investigators have been developed based on the data obtained in round tubes and/or tube bundles. Also, the weighted mean drift velocity by Ishii [19] has been confirmed experimentally that the model can be applicable to developing bubbly flow [20]. As such, the models of Hibiki et al. [11] and Ishii [19] reproduce the present data very well. Also, Fig. 4 confirms that the models predict the experimental data very well except for the conditions where the significant slug/cap bubbles were detected.

\subsection{Bubble layer thickness}

Subcooled boiling can be characterized by the existence of two distinctive flow regions, a bubble layer as two-phase region and a subcooled liquid region. Considering the boundary between the bubble layer and subcooled liquid regions to be the intersection of the abscissa and zero value of void fraction, Fig. 3 shows that the bubble layer thickness increases with heat flux and inlet temperature, and decreases with inlet liquid velocity. To predict the one-dimensional interfacial area concentration mechanistically in the subcooled boiling flow, Hibiki et al. [11] have introduced the bubble layer thickness model to avoid many covariances in cross-sectional averaged interfacial transport equation, and then formulated the one-dimensional interfacial transport equation by partitioning a flow region into two regions; boiling two-phase (bubble layer) region and liquid single-phase region. In the model, the square void peak in the bubble layer region was assumed to predict the bubble layer thickness of the subcooled boiling flow. The bubble layer thicknesses were derived analytically in an annulus in terms of the distribution parameter and the geometrical parameters of flow channel. So, the bubble layer thickness can be estimated provided that the distribution parameter is given. They also proposed the distribution parameter which is presented in Table 4. In this study, the present data are compared with the predictions by the bubble layer thickness

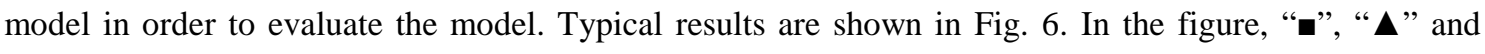
"•"indicate the measured void fraction profiles, and the solid lines with hatched area are the calculated void fraction profiles by the model. It can be seen that the bubble layer thickness model assuming the square void peak near a heater surface can approximate the measured void fraction profiles reasonably well. Thus, the bubble layer thickness model is considered to be applicable for predicting the bubble layer thickness to be used in the formulation of the one-dimensional interfacial transport equation in subcooled 
boiling flow.

\subsection{Interfacial area concentration}

Fig. 7 shows typical profiles of the measured local interfacial area concentration (IAC), $a_{i}$. The experimental condition in each graph of the figure is same as that in the corresponding graph in Fig. 3. Because the double-sensor conductivity probe method was developed under the assumption of spherical bubble shape [21], the measurements of the local interfacial area concentration and bubble Sauter mean diameter are generally not accurate for cap or slug bubbles. For data sets in Fig. 3, significant slug/cap bubbles were observed in the flow conditions of $q^{\prime \prime}=99.2 \mathrm{~kW} / \mathrm{m}^{2}, T_{\mathrm{in}}=98.0^{\circ} \mathrm{C}, v_{\mathrm{fi}}=0.50 \mathrm{~m} / \mathrm{s}$ at $z_{\mathrm{h}} / D_{\mathrm{H}}=68.7$ and $89.4, q^{\prime \prime}=150.0 \mathrm{~kW} / \mathrm{m}^{2}, T_{\mathrm{in}}=99.0^{\circ} \mathrm{C}, v_{\mathrm{fi}}=1.00 \mathrm{~m} / \mathrm{s}$ at $z_{\mathrm{h}} / D_{\mathrm{H}}=89.4$, and $q^{\prime \prime}=193.0 \mathrm{~kW} / \mathrm{m}^{2}, T_{\mathrm{in}}=95.0{ }^{\circ} \mathrm{C}$, $v_{\mathrm{fi}}=1.00 \mathrm{~m} / \mathrm{s}$ at $z_{\mathrm{h}} / D_{\mathrm{H}}=89.4$. Thus, the corresponding data are not shown in Fig. 7. Accordingly, the Sauter mean diameter data for such conditions are not shown in section of 3.4.

As shown in Fig. 7, the local interfacial area concentration distributions exhibit similar trends to the local void fraction distributions. The local interfacial area concentration reaches a maximum at about the same location as the void fraction peak. The interfacial area concentration is as high as $1100 \mathrm{~m}^{-1}$ near the heater surface, which indicates the high heat transfer rate associated with the subcooled boiling and the convection of the bubbles because the local transports of mass, momentum and energy are proportional to the interfacial area concentration. The interfacial area concentration depends on the bubble number density and the bubble size. Considering the relatively small change in bubble sizes compared with the change in interfacial area concentrations (see Fig.11), the major cause for the high interfacial area concentration in the vicinity of the heater surface is the presence of many bubbles generated on the heater surface. As the bulk subcooling increases along the radial direction, the bubbles are condensed and the interfacial area concentration decreases along the radial direction. As can be seen in the figure, the influences of flow conditions on the interfacial area concentration are similar to those on the void fraction, that is, the interfacial area concentration grows with an increase of heat flux, an increase of inlet liquid temperature, a decrease of inlet liquid velocity and a flow development along the flow direction.

As can be seen in Table 2, the flow range of present experiment covers up to $2 \mathrm{~m} / \mathrm{s}$ of inlet liquid velocity which is very higher than those of previous experiments that have been performed in low pressure conditions. It is expected that the local interfacial area concentration near the wall of heater surface in high flow condition will be higher than that in low flow condition for the same local void fraction because the higher turbulences induced by wall and bubbles could enhance the bubble breakup. This is shown in Fig. 8 where the local interfacial area concentrations at $z_{\mathrm{h}} / D_{\mathrm{H}}=89.4$ of Fig. 7 are plotted against local void fractions. The local interfacial area concentrations are shown to increase slightly with inlet liquid velocity for the same local void fraction. However, strong dependency of local interfacial area concentration on liquid flow is not found for the flow range of present experiment.

Fig. 9 shows the axial development of the area-averaged interfacial area concentration, $\left\langle a_{i}\right\rangle$ as a function of the thermal equilibrium quality. The symbols in the figure indicate the experimental data, and the solid and broken lines denote the area-averaged interfacial area concentrations calculated by the model 
proposed by Hibiki et al. [24] which is shown in Table 6. The trend of average interfacial area concentrations is shown to be similar to that of averaged void fraction. It is expected if considering the similarity in the profiles of local void fraction and interfacial area concentration. The area-averaged interfacial area concentration increases mainly as a result of more phase change along the flow direction because the pressure drop along the flow channel was less than $0.03 \mathrm{MPa}$ as indicated in Table 3.

The average interfacial area concentrations with bubbly flow regime for data sets in Table 3 were compared with the predictions by several existing correlations. Even though many correlations were proposed for adiabatic two-phase flow, the correlations based on steam-water data have been limited so far mainly due to the lack of experimental data. Zeitoun et al. [22] have evaluated the available correlations developed on the basis of adiabatic gas-liquid flow. They compared the predictions by those correlations with the data obtained in steam-water condensing flow. It was shown that those correlations were unable to predict their measured data accurately. In this study, four existing correlations [7, 22, 23, 24] were evaluated to examine the applicability of those models to subcooled boiling flow, which were developed based on steam-water data or could be applicable to developing flow. They are listed in Table 6.

The model of Zeitoun et al. [22] was developed based on the data obtained in the subcooled steam-water flow in an unheated annular test section. They also found a strong dependency of interfacial area concentration on void fraction and proposed another form of simple correlation as a function of void fraction only. Zeitoun and Shoukri [7] measured the interfacial area concentration in subcooled boiling flow in a vertical annulus using the high-speed video system. Considering the effects of heat flux, mass flux and liquid subcooling, they developed the correlation for mean bubble diameter which can be expressed as the equation in Table 6 using the following geometric relation between the interfacial area concentration, $\left\langle a_{i}\right\rangle$, the void fraction, $\langle\alpha\rangle$ and the Sauter mean diameter, $\left\langle D_{\mathrm{sm}}\right\rangle$.

$$
<D_{s m}>=6<\alpha>/<a_{i}>
$$

Hibiki and Ishii [23] developed a semi-theoretical model from the interfacial area transport equation to predict the interfacial area concentration of adiabatic gas-liquid flow. They validated the model for extensive range of channel geometries, flow conditions and physical properties. Although the model was developed based on the data which were obtained under the fully developed adiabatic flow condition, the correlation deduced the flow parameter dependence on interfacial area concentration from the interfacial area transport equation considering the hydrodynamic effect. Thus, in view of the importance of the interfacial area transport equation, their model was tested to check the applicability to the subcooled boiling flow. Recently, Hibiki et al [24] proposed the model which could be applicable to the prediction of interfacial area concentration in subcooled boiling flow. Using the available subcooled boiling data, they modified the previous correlation [23] to extend the applicable range to the subcooled boiling flow.

Fig. 10 shows comparisons between the experimental data and the predictions by the correlations listed in Table 6. Also, Table 7 shows the average deviation between the prediction and the data and the applicable geometry for each correlation. The prediction error for $\left\langle a_{i}\right\rangle$ is defined in the same way as Eq. 
(3), and the average deviation is obtained by averaging the prediction errors for whole data. The model of Hibiki et al. [24] predicts the measurement data quite well, which also can be seen in Fig. 9. On the other hand, Hibiki and Ishii' model [23] predicts the data reasonably well. However, the interfacial area concentrations are underestimated for very low void fraction range, and overestimated for high void fraction range. As pointed out in the study of Hibiki et al. [24], this error was caused by the approximation for dependency of interfacial area concentration on void fraction, which was found to be different between adiabatic bubbly flow and subcooled boiling flow. Using the data [10] obtained in subcooled boiling flow, they determined the proper void fraction dependency applicable to subcooled boiling flow. Actually, above two correlations were derived from the interfacial area transport equation based on the assumption that the increase rate of bubble number density due to bubble nucleation and the decrease rate of bubble number density due to bubble condensation are zero. This assumption can also be regarded as the equivalence of contributions by bubble nucleation and condensation. Thus, the fact that above correlations works well implies the bubble condensation effect compensates for bubble nucleation effect in subcooled boiling flow for the experimental conditions in Table 3. The correlation of Zeitoun and Shoukri [7] underestimates the measured interfacial area concentrations. Their correlation was developed on the basis of measured bubble size in low flow condition compared with the present experiment as shown in Table 2. They observed that the bubble coalescence was intensified downstream of the net vapor generation point and was caused by the increase in bubble size and bubble growth-collapse period. This observation may imply that many large bubbles like slug bubbles existed along with small bubbles near the heater surface in that region. The existence of slug bubbles causes lower interfacial area concentration for the same average void fraction when compared with that in bubbly flow regime. In the present experiment, the interfacial area concentration was acquired only in bubbly flow regime. This difference can be partly attributed to the underestimation of the present data. The correlation of Zeitoun et al. [22] also under-predicts the data. In condensing flow in an unheated annulus, there are no small sizes of detached bubbles which cause large local interfacial area concentrations near the heater surface. In addition, the maximum bubble size observed in their experiment was in the order of $7 \mathrm{~mm}$ which is larger than the bubble sizes in the present experiment (see Fig.11). The lower prediction by the correlation based on the data obtained in condensing steam-water flow can be caused by these considerations.

\subsection{Sauter mean diameter}

Fig. 11 shows the profiles of measured local bubble Sauter mean diameter, $D_{\text {sm. }}$ The experimental condition in each graph of the figure is same as that in the corresponding graph in Fig. 7. As shown in the Fig. 11, the changes in the Sauter mean diameter profiles are relatively small compared with the changes in the void fraction and interfacial area concentration profiles. The Sauter mean diameter increases near the heater surface and then decreases as bubbles move toward the outer wall. Near the heater surface, the bubble size increases due to the bubble growth on the heater surface and the bubble coalescence away from the heater surface. The bubble size decreases due to the condensation as bubbles move toward the subcooled liquid region. As the average void fraction increases, the radial profile of Sauter mean diameter 
tends to be uniform. For high average void fraction conditions where the bubble layers extend to channel outer wall, the bubble diameters near the outer wall are about $2 \mathrm{~mm}$ independent of flow conditions. This implies that the bulk temperature is around saturation temperature and bubbles would not condense. Also, as can be seen in second graph of third row in Fig. 11, the profiles of Sauter mean diameter at $v_{\mathrm{fi}}=2.0 \mathrm{~m} / \mathrm{s}$ are nearly uniform when compared with those for lower inlet liquid velocity than $2.0 \mathrm{~m} / \mathrm{s}$. The bubble breakup in the bubble layer seems to be more dominant than the bubble coalescence at this high flow condition. The effects of flow conditions on the radial profile of Sauter mean diameter is similar to those on the void fraction profile. The bubble Sauter mean diameters increase with the heat flux and inlet temperature, and they decrease with the inlet liquid velocity. Sauter mean diameter also increases along the flow direction. The bubble coalescence and the bubble expansion due to the local pressure reduction contribute to the growth of bubble size along the flow direction.

The area-averaged Sauter mean diameter can be calculated using models listed in Table 6 since the area-averaged Sauter mean diameter is given by Eq. (6). The experimental data with bubbly flow regime in Table 3 were compared with the predictions by the models in Table 6 and Eq. (6), and the average deviations are represented in Table 7.

\section{Conclusions}

Fundamental experiments for obtaining an accurate knowledge of distributions of local two-phase flow parameters are essential for the development of a reliable interfacial area transport equation. From this point of view, the axial development of local void fraction, interfacial area concentration and bubble Sauter mean diameter were measured in a BWR-scaled vertical annulus for the subcooled boiling flow of water. At atmospheric system pressure, the local measurements were performed at four axial locations of $z_{\mathrm{h}} / D_{\mathrm{H}}$ of $31.3,52.6,68.7$, and 89.4 as well as radial locations between $r /\left(R-R_{0}\right)$ of 0.05 and 0.90 using the double-sensor conductivity probe method. A total of 10 data sets were acquired under four heat fluxes of 50,100, 150 and $193 \mathrm{~kW} / \mathrm{m}^{2}$, three inlet liquid temperatures of 95,98 and $99{ }^{\circ} \mathrm{C}$, and three inlet liquid velocities of $0.5,1.0$ and $2.0 \mathrm{~m} / \mathrm{s}$. From the scaling consideration for a prototypic BWR, the flow range of present experiment was extended to $2.0 \mathrm{~m} / \mathrm{s}$.

Combining these measurement data with the previous data [10] obtained in the present experimental facility, the influences of flow conditions on the radial profiles of local two-phase flow parameters and their axial developments were discussed.

The measured area-averaged void fraction and interfacial area concentration were compared with the predictions by the existing correlations for drift-flux parameters and interfacial area concentration. Six correlations for drift-flux parameters were evaluated to examine the applicability of those models to subcooled boiling flow. Most of the correlations predict the data well for average void fraction higher than about $1 \%$. However, for average void fraction lower than about $1 \%$, only the models of Hibiki et al. [11] and Ishii [19] could reproduce the measurement data well. The prediction accuracies of the models were estimated to be $\pm 8.4 \%$ for average void fraction and $\pm 8.5 \%$ for distribution parameter. For the area-averaged interfacial area concentration, four existing correlations were evaluated. Among the models, 
only the semi-theoretical model of Hibiki et al. [24] could predict the measured interfacial area concentrations quite well for the entire tested void fraction range with the accuracy of $\pm 13.4 \%$

The bubble-layer thickness model for the subcooled boiling in the internally heated annulus was also compared with the experimental data. The model could approximate the bubble-layer thickness for the subcooled boiling flow in an internally heated annulus reasonably well.

\section{Acknowledgements}

This work was supported by the Tokyo Electric Power Company (TEPCO) and the Post-doctoral Fellowship Program of Korea Science \& Engineering Foundation (KOSEF).

\section{References}

[1] J.M. Kelly, Thermal-hydraulic modeling needs for passive reactors, in: Proceedings of OECD/CSNI Special Meeting on Advanced Instrumentation and Measurement Techniques, Santa Barbara, CA, 1997.

[2] G. Kocamustafaogullari, M. Ishii, Foundation of the interfacial area transport equation and its closure relations, International Journal of Heat and Mass Transfer 38 (3) (1995) 481-493.

[3] J.M. Delhaye, R. Semeria, J.C. Flamand, Void fraction, vapor and liquid temperatures; local measurements in two-phase flow using a microthermocouple, ASME Journal of Heat Transfer 95 (1973) 365-370.

[4] K. Sekoguchi, H. Fukui, Y. Sato, Flow boiling in subcooled and low quality regions heat transfer and local void fraction, in: Proceedings of fifth International Heat Transfer conference, Tokyo, Japan, 1974, Vol. 4, 180-184.

[5] A. Hasan, R.P. Roy, S.P. Kalra, Some Measurements in Subcooled Flow Boiling of Refrigerant-113, ASME Journal of Heat Transfer 113 (1991) 216-223.

[6] R.P. Roy, V. Velidandla, S.P. Kalra, P. Peturaud, Local Measurements in the Two-Phase Region of Turbulent Subcooled Boiling Flow, ASME Journal of Heat Transfer 116 (1994) 660-669.

[7] O. Zeitoun, M. Shoukri, Bubble behavior and mean bubble diameter in subcooled flow boiling, ASME Journal of Heat Transfer 118 (1996) 110-116.

[8] J. Garnier, E. Manon, G. Cubizolles, Local measurements on flow boiling of refrigerant 12 in a vertical tube, Multiphase Science and Technology 13 (2001) 1-111.

[9] T.H. Lee, G.C. Park, D.J. Lee, Local flow characteristics of subcooled boiling flow of water in a vertical concentric annulus, International Journal of Multiphase Flow 28 (8) (2002) 1351-1368.

[10] R. Situ, T. Hibiki, X. Sun, Y. Mi, M. Ishii, Axial development of subcooled boiling flow in an internally heated annulus, Experiments in Fluids 37 (2004) 589-603.

[11] T. Hibiki, R. Situ, Y. Mi, M. Ishii, Modeling of bubble-layer thickness for formulation of one-dimensional interfacial area transport equation in subcooled boiling two-phase flow International Journal of Heat Mass Transfer, 46 (8) (2003) 1409-1423. 
[12] R. Situ, T. Hibiki, X. Sun, Y. Mi, M. Ishii, Flow structure of subcooled boiling flow in an internally heated annulus, International Journal of Heat and Mass Transfer 47 (24) (2004) 5351-5364.

[13] T. Hibiki, R. Situ, Y. Mi, M. Ishii, Local flow measurements of vertical upward bubbly flow in an annulus, International Journal of Heat and Mass Transfer 46 (8) (2003) 1479-1496.

[14] N. Zuber, J.A. Findlay, Average volumetric concentration in two-phase flow system, ASME Journal of Heat Transfer 87 (1965) 453-468.

[15] General Electric Company, Qualification of the one-dimensional core transient model for boiling water reactors, NEDO-24154, USA, 1970.

[16] D.R.H. Beattie, S. Sugawara, Steam-water void fraction for vertical upflow in a $73.9 \mathrm{~mm}$ pipe, International Journal of Multiphase Flow 12 (4) (1986) 641-653.

[17] K. Kawanishi, Y. Hirao, A. Tsuge, A., An experimental study on drift flux parameters for two-phase flow in vertical round tube, Nuclear Engineering and Design 120 (1990) 447-458.

[18] B. Chexal, G. Lellouche, J. Horowitz, J. Healzer, A void fraction correlation for generalized application, Progress in Nuclear Energy 27 (4) (1992) 255-295.

[19] M. Ishii, One-dimensional drift-flux model and constitutive equations for relative motion between phases in various two-phase flow regimes, ANL-7747, USA, 1977.

[20] T. Hibiki, M. Ishii, Distribution parameter and drift velocity of drift-flux model in bubbly flow, International Journal of Heat and Mass Transfer 45 (4) (2002) 707-721.

[21] Q. Wu, M. Ishii, Sensitivity study on double-sensor conductivity probe for the measurement of interfacial area concentration in bubbly flow, International Journal of Multiphase Flow 25 (1) (1999) 155-173.

[22] O. Zeitoun, M. Shoukri, V. Chatoorgoon, Measurement of interfacial area concentration in subcooled liquid-vapour flow, Nuclear Engineering and Design 152 (1994) 243-255.

[23] T. Hibiki, M. Ishii, Interfacial area concentration of bubbly flow systems, Chemical Engineering Science 57 (2002) 3967-3977.

[24] T. Hibiki, T.H. Lee, J.Y. Lee, M. Ishii, Interfacial area concentration in boiling bubbly flow systems, Chemical Engineering Science 61 (2006) 7979-7990. 


\section{Caption of Tables}

Table 1. Prototypic BWR conditions and experimental conditions in the present experiment

Table 2. Experimental works on local measurements in subcooled boiling flow

Table 3. Experimental conditions

Table 4. Existing correlations of drift-flux parameters

Table 5. Prediction error and applicable geometry for existing correlations of drift-flux parameters

Table 6. Existing correlations of interfacial area concentration

Table 7. Prediction error and applicable geometry for existing correlations of interfacial area concentration

\section{Captions of Figures}

Fig. 1. Schematic diagram of test loop

Fig. 2. Experimental conditions in present and previous works on local measurements in subcooled boiling flow

Fig. 3. Local void fraction profiles

Fig. 4. Axial development of area-averaged void fraction

Fig. 5. Comparison of the measured average void fraction and distribution parameter with the predictions by existing correlations

Fig. 6. Comparison of void fraction profiles predicted by bubble-layer thickness model with the measured data

Fig. 7. Local interfacial area concentration profiles

Fig. 8. Variation of local interfacial area concentration according to local void fraction change

Fig. 9. Axial development of area-averaged interfacial area concentration

Fig. 10. Comparison of the measured average interfacial area concentration with the predictions by existing correlations

Fig. 11. Local bubble Sauter mean diameter profiles 
Table 1. Prototypic BWR conditions and experimental conditions in the present experiment

\begin{tabular}{lll}
\hline Quantity & Prototype & Present experiment \\
\hline Pressure $(\mathrm{MPa})$ & 7.17 & 0.101 \\
Saturation Temperature $\left({ }^{\circ} \mathrm{C}\right)$ & 287 & 100 \\
Heater Diameter, $D_{\mathrm{rod}} \quad(\mathrm{m})$ & 0.0123 & 0.0191 \\
Hydraulic Diameter, $D_{\mathrm{H}}(\mathrm{m})$ & 0.0150 & 0.0191 \\
Heated Length $(\mathrm{m})$ & 3.81 & 1.73 \\
Heater Power $(\mathrm{kW})$ & 77.2 & 20.0 \\
Heat Flux $\left(\mathrm{kW} / \mathrm{m}^{2}\right)$ & 526 & 193 \\
Bubble diameter, $D_{\mathrm{b}}(\mathrm{mm})$ & 3.18 & 5.01 \\
$D_{b} / D_{H}$ & 0.212 & 0.263 \\
Bubble Rise Velocity, $v_{\mathrm{r}}(\mathrm{m} / \mathrm{s})$ & 0.172 & 0.222 \\
Liquid Inlet Velocity, $v_{\mathrm{fi}}(\mathrm{m} / \mathrm{s})$ & 1.93 & $0.502 \sim 2.02$ \\
Reynolds Number, $N_{R e}$ & $2.24 \times 10^{5}$ & $3.16 \times 10^{4} \sim 1.27 \times 10^{5}$ \\
Weber Number, $N_{W e}$ & 4.00 & 4.00 \\
Subcooling Number, $N_{\text {sub }}$ & 0.650 & $19.1 \sim 32.2$ \\
Zuber $\left(\right.$ Phase Change) Number, $N_{\mathrm{Zu}}$ & 4.72 & $10.6 \sim 42.2$ \\
Inlet Subcooling $\left({ }^{\circ} \mathrm{C}\right)$ & 9.49 & $7.96 \sim 14.6$ \\
$\left(D_{\mathrm{b}} / D_{\mathrm{rod}}\right)_{\mathrm{R}}$ & & 1.01 \\
$\left(D_{\mathrm{b}} / D_{\mathrm{H}}\right)_{\mathrm{R}}$ & & 1.24 \\
$\left(N_{W e}\right)_{\mathrm{R}}$ & & 1.00 \\
$\left(v_{\mathrm{r}} / v_{\mathrm{fi}}\right)_{\mathrm{R}}$ & & $1.23 \sim 4.96$ \\
$\left(N_{\text {sub }}\right)_{\mathrm{R}}$ & & $29.3 \sim 49.5$ \\
$\left(N_{\mathrm{Zu}}\right)_{\mathrm{R}}$ & $5.83 \sim 16.7$ \\
\hline
\end{tabular}


Table 2. Experimental works on local measurements in subcooled boiling flow

\begin{tabular}{|c|c|c|c|c|c|c|c|}
\hline Investigators & $\begin{array}{l}\text { Geometry } \\
D_{H}(\mathrm{~mm})\end{array}$ & Fluid & $\begin{array}{c}P \\
(\mathrm{kPa}) \\
\end{array}$ & $\begin{array}{c}q^{\prime \prime} \\
\left(\mathrm{kW} / \mathrm{m}^{2}\right)\end{array}$ & $\begin{array}{c}G \\
\left(\mathrm{~kg} / \mathrm{m}^{2} \mathrm{~s}\right)\end{array}$ & $\begin{array}{l}\Delta T_{\text {sub }} \\
\left({ }^{\circ} \mathrm{C}\right) \\
\end{array}$ & $\begin{array}{c}v_{\mathrm{fi}} \\
(\mathrm{m} / \mathrm{s}) \\
\end{array}$ \\
\hline \multirow{4}{*}{$\begin{array}{l}\text { Sekoguchi et } \\
\text { al. }^{\text {a }}[4]\end{array}$} & Circular & \multirow{4}{*}{ Water } & & & & & \\
\hline & 11.0 & & 137-196 & $47-163$ & $295-669$ & $15.0-55.0$ & $0.31-0.71$ \\
\hline & 13.6, & & $196-1570$ & $116-465$ & $318-1815$ & $11.0-98.0$ & $0.38-2.10$ \\
\hline & 15.8 & & 785 & $291-1745$ & 898 & $15.0-97.0$ & 1.00 \\
\hline $\begin{array}{c}\text { Hasan et al. } \\
{[5]}\end{array}$ & $\begin{array}{c}\text { Annular } \\
22.2\end{array}$ & R-113 & $184-253$ & $42-140$ & $579-801$ & $20.0-37.0$ & $0.40-0.56$ \\
\hline Roy et al. [6] & $\begin{array}{c}\text { Annular } \\
22.2\end{array}$ & $\mathrm{R}-113$ & 269 & $79-126$ & 579,801 & $29.8-37.1$ & $0.41,0.56$ \\
\hline $\begin{array}{c}\text { Zeitoun et al. } \\
\text { [7] }\end{array}$ & $\begin{array}{c}\text { Annular } \\
25.4\end{array}$ & Water & $117-168$ & $287-706$ & $151-412$ & $11.6-31.1$ & $0.16-0.43$ \\
\hline $\begin{array}{c}\text { Garnier et al. } \\
{[8]}\end{array}$ & $\begin{array}{c}\text { Circular } \\
19.2\end{array}$ & $\mathrm{R}-12$ & $1458-3010$ & $58-135$ & $1007-5060$ & - & $1.05-4.30$ \\
\hline Lee et al. [9] & $\begin{array}{c}\text { Annular } \\
18.5\end{array}$ & Water & $100-153$ & $88-351$ & $470-1061$ & $10.2-21.4$ & $0.50-1.10$ \\
\hline Situ et al. [10] & $\begin{array}{c}\text { Annular } \\
19.1\end{array}$ & Water & $110-128$ & $99-151$ & $475-1184$ & $8.3-13.1$ & $0.50-1.24$ \\
\hline $\begin{array}{c}\text { Present } \\
\text { experiment }\end{array}$ & $\begin{array}{c}\text { Annular } \\
19.1\end{array}$ & Water & $110-131$ & $50-193$ & $478-1917$ & $8.0-14.6$ & $0.50-2.02$ \\
\hline
\end{tabular}


Table 3. Experimental conditions

\begin{tabular}{|c|c|c|c|c|c|c|}
\hline & Set & $\begin{array}{c}q^{\prime \prime} \\
\left(\mathrm{kW} / \mathrm{m}^{2}\right)\end{array}$ & $\begin{array}{c}T_{\text {in }} \\
\left({ }^{\circ} \mathrm{C}\right) \\
\end{array}$ & $\begin{array}{c}v_{\mathrm{fi}} \\
(\mathrm{m} / \mathrm{s}) \\
\end{array}$ & $\begin{array}{c}\Delta P \\
(\mathrm{kPa}) \\
\end{array}$ & $\begin{array}{c}P_{\text {in }} \\
(\mathrm{kPa}) \\
\end{array}$ \\
\hline \multirow{11}{*}{ Situ et al. [10] } & 1 & 98.7 & 95.0 & 0.665 & 22.1 & 129.1 \\
\hline & 2 & 99.6 & 95.0 & 0.970 & 16.8 & 132.2 \\
\hline & 3 & 101 & 95.0 & 1.190 & 12.7 & 134.4 \\
\hline & 4 & 151 & 95.0 & 0.662 & 29.9 & 129.1 \\
\hline & 5 & 149 & 95.0 & 0.994 & 20.1 & 132.1 \\
\hline & 6 & 150 & 95.0 & 1.240 & 21.0 & 132.9 \\
\hline & 7 & 150 & 98.0 & 1.230 & 20.6 & 135.8 \\
\hline & 8 & 151 & 98.0 & 0.987 & 19.9 & 133.6 \\
\hline & 9 & 98.1 & 98.0 & 0.997 & 20.2 & 133.1 \\
\hline & 10 & 99.2 & 98.0 & 0.502 & 16.5 & 126.2 \\
\hline & 11 & 99.6 & 95.0 & 0.498 & 19.1 & 128.2 \\
\hline \multirow{10}{*}{$\begin{array}{c}\text { Present } \\
\text { experiment }\end{array}$} & 12 & 193 & 95.0 & 2.016 & 23.7 & 141.3 \\
\hline & 13 & 193 & 98.0 & 1.999 & 24.6 & 146.3 \\
\hline & 14 & 193 & 99.0 & 1.993 & 24.6 & 148.1 \\
\hline & 15 & 150 & 99.0 & 1.988 & 25.1 & 145.0 \\
\hline & 16 & 193 & 95.0 & 1.004 & 20.7 & 132.3 \\
\hline & 17 & 50.0 & 99.0 & 1.000 & 21.5 & 131.9 \\
\hline & 18 & 100 & 99.0 & 0.996 & 21.1 & 135.0 \\
\hline & 19 & 150 & 99.0 & 0.995 & 21.5 & 136.8 \\
\hline & 20 & 50.0 & 98.0 & 0.502 & 20.8 & 128.4 \\
\hline & 21 & 50.0 & 99.0 & 0.505 & 20.2 & 129.2 \\
\hline
\end{tabular}


Table 4. Existing correlations of drift-flux parameters

\begin{tabular}{|c|c|}
\hline Investigators & Correlations \\
\hline Ishii [19] and & $C_{0}=\left(1.2-0.2 \sqrt{\rho_{g} / \rho_{f}}\right)\left[1-\exp \left(-3.12\langle\alpha\rangle^{0.212}\right)\right]$ \\
\hline Hibiki et al. [11] & $V_{g j}=\sqrt{2}\left(\frac{g \sigma\left(\rho_{f}-\rho_{g}\right)}{\rho_{f}^{2}}\right)^{1 / 4}(1-\langle\alpha\rangle)^{1.75} \quad$ for bubbly flow regime \\
\hline Chexal et al. [18] & $\begin{array}{l}C_{o}=C_{o v} \quad \text { for vertical steam-water flow } \\
C_{o v}=L /\left[K_{o}+\left(1-K_{o}\right)<\alpha>^{r}\right], \quad L=\left[\frac{1-\exp \left(-C_{1}<\alpha>\right)}{1-\exp \left(-C_{1}\right)}\right] \\
C_{1}=4 P_{\text {crit }}^{2} /\left[P\left(P_{\text {crit }}-P\right)\right], \quad K_{o}=B_{1}+\left(1-B_{1}\right)\left(\frac{\rho_{g}}{\rho_{f}}\right)^{1 / 4} \\
r=\left(1+1.57 \rho_{g} / \rho_{f}\right) /\left(1-B_{1}\right), \quad B_{1}=\min \left(0.8, A_{1}\right) \\
A_{1}=1 /[1+\exp (-\operatorname{Re} / 60000)] \\
\operatorname{Re}=\operatorname{Re}_{g} \text { if } \operatorname{Re}_{g}>\operatorname{Re}_{f}, \quad \operatorname{Re}=\operatorname{Re}_{f} \text { if } \operatorname{Re}_{g}<\operatorname{Re}_{f} \\
V_{g j}=V_{g i v}^{o} C_{9} \quad \text { for vertical flow } \\
V_{g j v}^{o}=1.41\left[\frac{\left(\rho_{f}-\rho_{g}\right) \sigma g}{\rho_{f}^{2}}\right]^{0.25} \quad C_{2} C_{3} C_{4} \\
\text { for } \operatorname{Re}_{g} \geq 0 C_{9}=(1-<\alpha>)^{B_{1}}, \quad \text { for } \operatorname{Re}_{g}<0 C_{9}=\min \left(0.7,(1-<\alpha>)^{0.65}\right) \\
\text { for } \rho_{f} / \rho_{g} \leq 18 C_{2}=0.4757\left[\ln \left(\rho_{f} / \rho_{g}\right)\right]^{0.7} \\
\text { for } \operatorname{Re}_{g}>18 \quad C_{2}=1 \text { if } C_{5} \geq 1, \quad 1 /\left\{1-\exp \left[-C_{5} /\left(1-C_{5}\right)\right]\right\} \text { if } C_{5}<1 \\
C_{5}=\sqrt{150 /\left(\rho_{f} / \rho_{g}\right)} \\
C_{4}=1 \text { if } C_{7} \geq 1,1 /\left[1-\exp \left(-C_{8}\right)\right] \text { if } C_{7}<1 \\
C_{7}=\left(D_{2} / D_{H}\right)^{0.6}, \quad C_{8}=C_{7} /\left(1-C_{7}\right), \quad D_{2}=0.09144 m \\
C_{3}=\max \left(0.5,2 \exp \left[-\operatorname{Re}_{f} / 60000\right]\right) \\
\text { for upflow }\end{array}$ \\
\hline Kawanishi et al. [17] & $\begin{array}{l}\text { for }<j>>0 \\
\text { for } P \leq 1.5 \mathrm{MPa},<j>>0.24, D \leq 0.05\end{array}$ \\
\hline Beattie et al. [16] & $\begin{array}{l}C_{0}=1+2.6 \sqrt{f}, \quad f=5.525 \times 10^{-2}\left[\frac{D G}{3 \mu_{f}}\right]^{-0.237}+8.0 \times 10^{-4} \\
V_{g j}=1.4\left(\frac{g \sigma\left(\rho_{f}-\rho_{g}\right)}{\rho_{f}^{2}}\right)^{1 / 4} \quad \text { for bubbly flow }\end{array}$ \\
\hline GE [15] & $\begin{aligned} C_{0} & =1.1 \\
V_{g j} & =2.9\left(\frac{g \sigma\left(\rho_{f}-\rho_{g}\right)}{\rho_{f}^{2}}\right)^{1 / 4}\end{aligned}$ \\
\hline Zuber and Findlay [14] & $\begin{array}{l}C_{0}=1.13 \\
V_{g j}=1.41\left(\frac{g \sigma\left(\rho_{f}-\rho_{g}\right)}{\rho_{f}^{2}}\right)^{1 / 4}\end{array}$ \\
\hline
\end{tabular}


Table 5. Prediction error and applicable geometry for existing correlations of drift-flux parameters

\begin{tabular}{lccc}
\hline \multicolumn{1}{c}{ Correlation } & $\begin{array}{c}\text { Average deviation } \\
\text { for }<\alpha\rangle\end{array}$ & $\begin{array}{c}\text { Average deviation } \\
\text { for } C_{o}\end{array}$ & Applicable geometry \\
\hline Ishii [19] and & $\pm 8.40 \%$ & $\pm 8.50 \%$ & annulus \\
Hibiki et al. [11] & $\pm 34.5 \%$ & $\pm 35.7 \%$ & pipe, bundle \\
Chexal et al. [18] & $\pm 20.5 \%$ & $\pm 37.8 \%$ & pipe \\
Kawanishi et al. [17] & $\pm 30.2 \%$ & $\pm 53.5 \%$ & pipe \\
Beattie et al. [16] & $\pm 32.5 \%$ & $\pm 30.4 \%$ & pipe, bundle \\
GE [15] & $\pm 21.3 \%$ & $\pm 30.4 \%$ & pipe \\
Zuber and Findlay [14] & & \\
\hline
\end{tabular}


Table 6. Existing correlations of interfacial area concentration

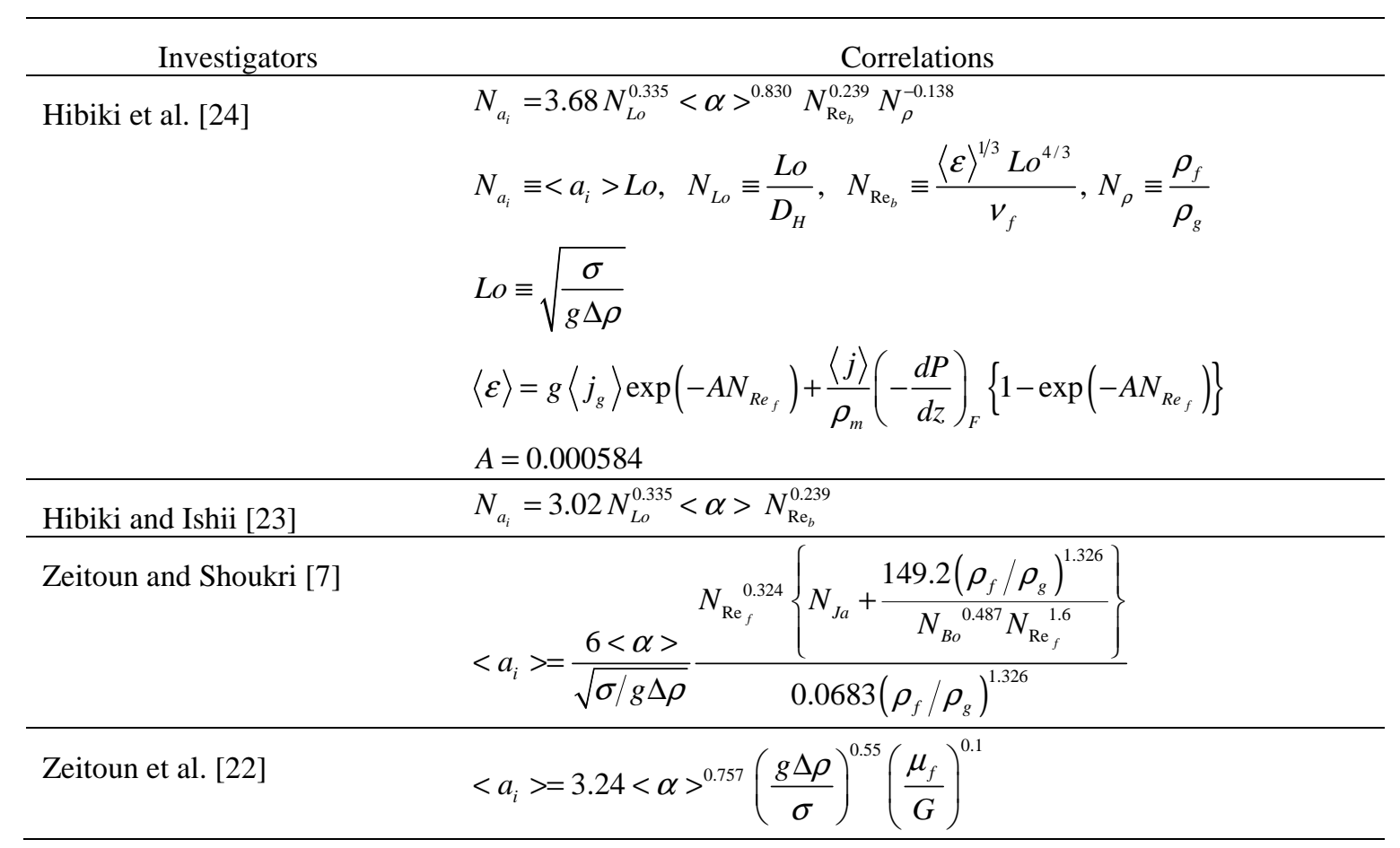


Table 7. Prediction error and applicable geometry for existing correlations of interfacial area concentration

\begin{tabular}{lccc}
\hline \multicolumn{1}{c}{ Correlation } & $\begin{array}{c}\text { Average deviation } \\
\left.\text { for }<a_{i}\right\rangle\end{array}$ & $\begin{array}{c}\text { Average deviation } \\
\text { for }<D_{s m}>\end{array}$ & Applicable geometry \\
\hline Hibiki et al. [24] & $\pm 13.4 \%$ & $\pm 13.3 \%$ & pipe, annulus, bundle \\
Hibiki and Ishii [23] & $\pm 31.8 \%$ & $\pm 26.4 \%$ & pipe, annulus, bundle \\
Zeitoun and Shoukri [7] & $\pm 40.2 \%$ & $\pm 71.7 \%$ & annulus \\
Zeitoun et al. [22] & $\pm 48.7 \%$ & $\pm 99.1 \%$ & annulus \\
\hline
\end{tabular}


Fig. 1

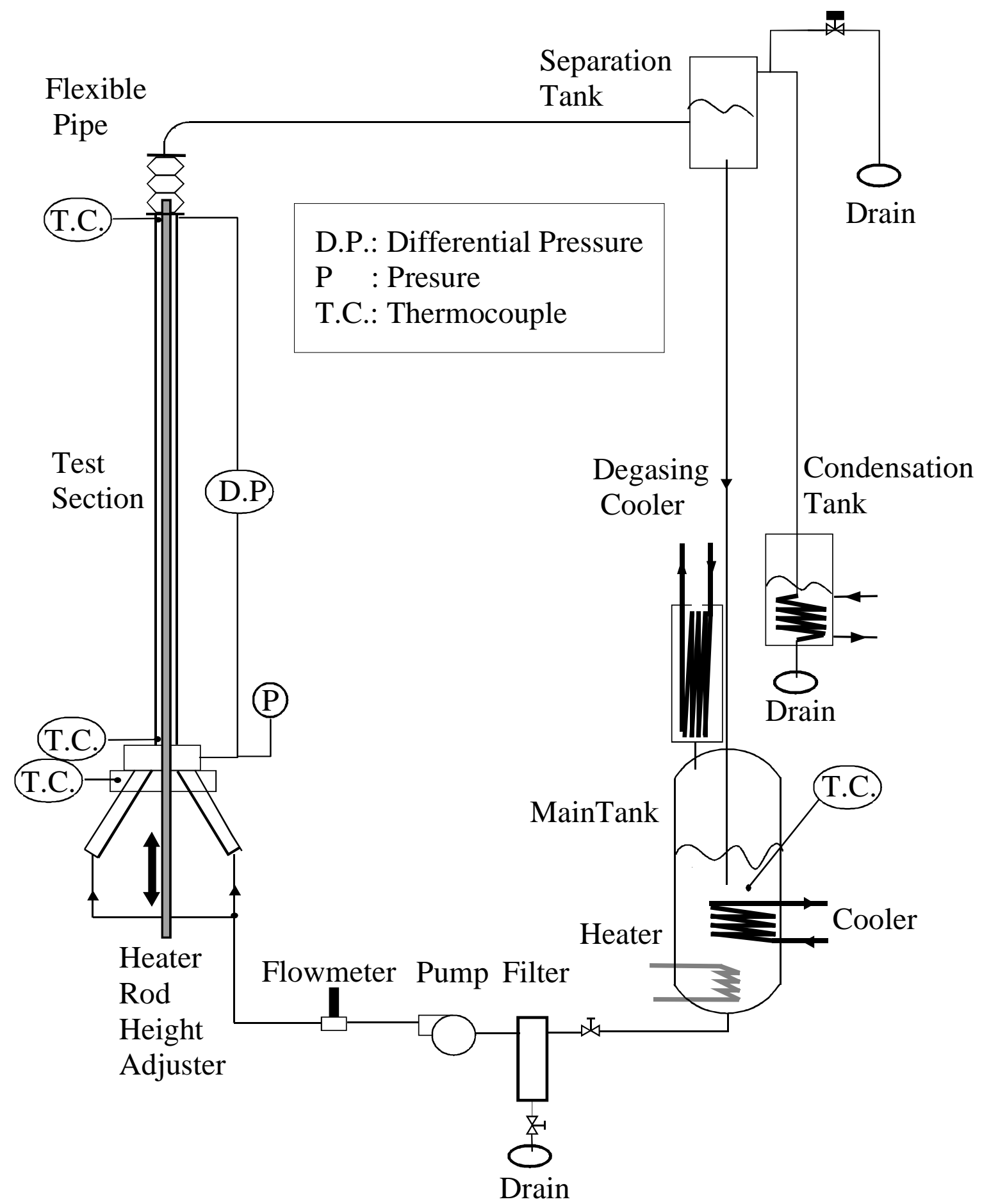


Fig. 2

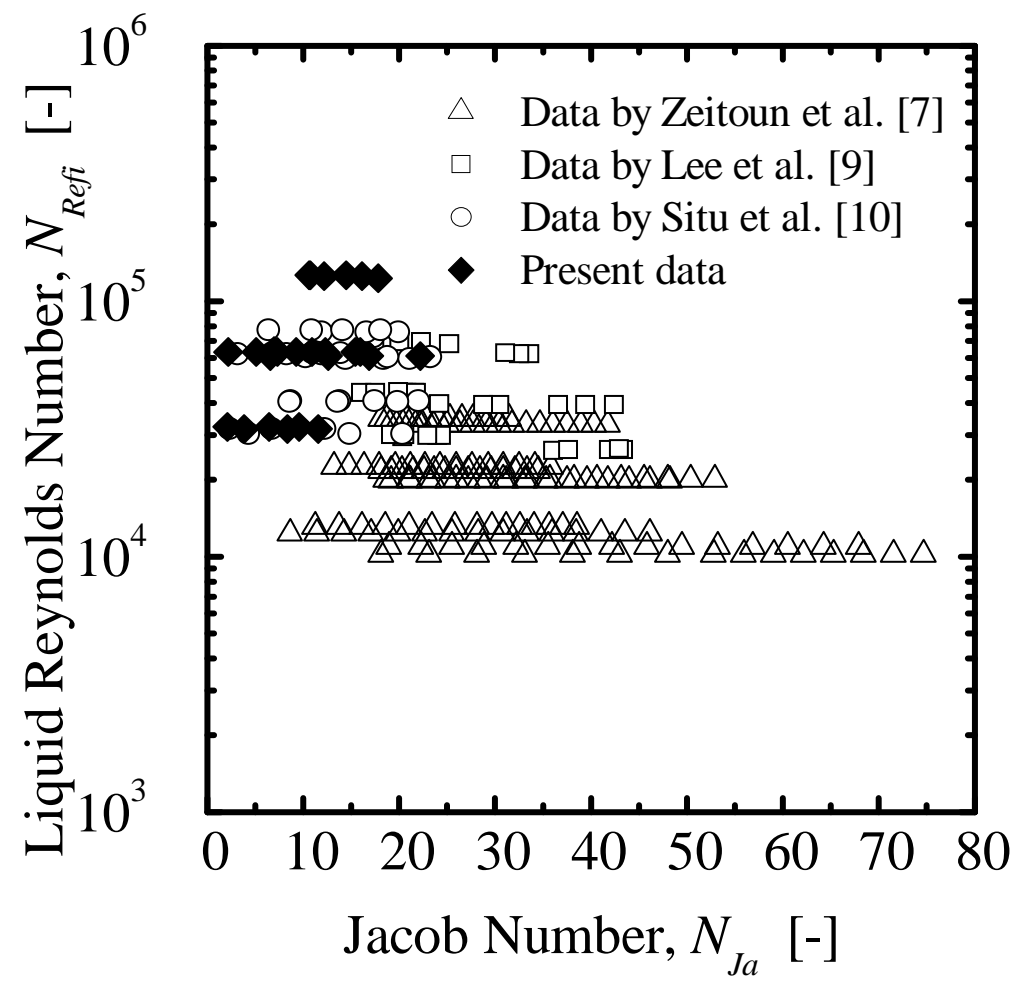


Fig. 3
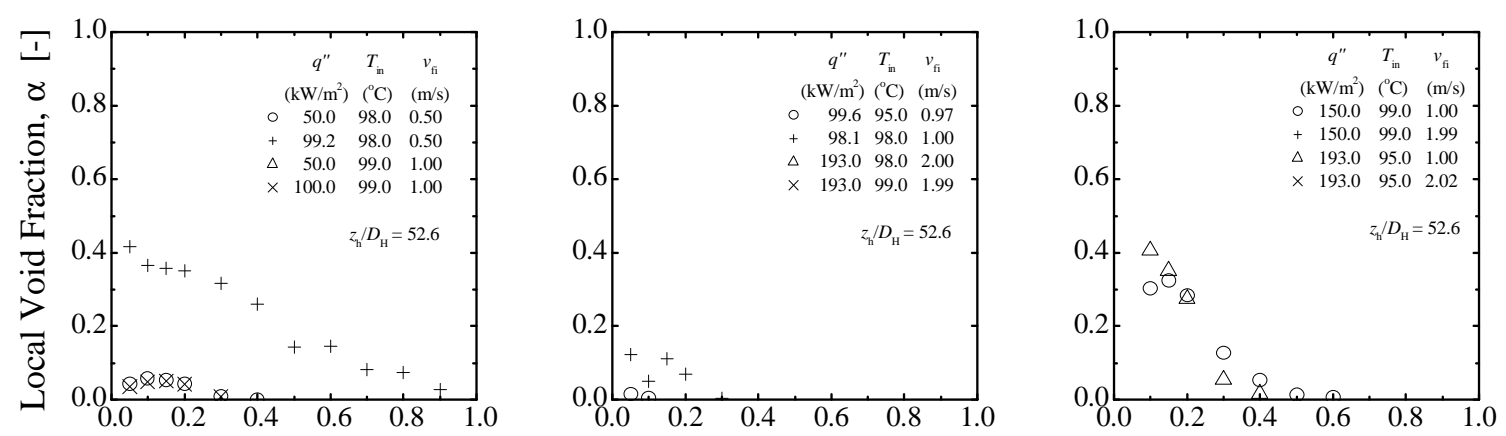

Radial Position, $r /\left(R-R_{o}\right)$ [-]
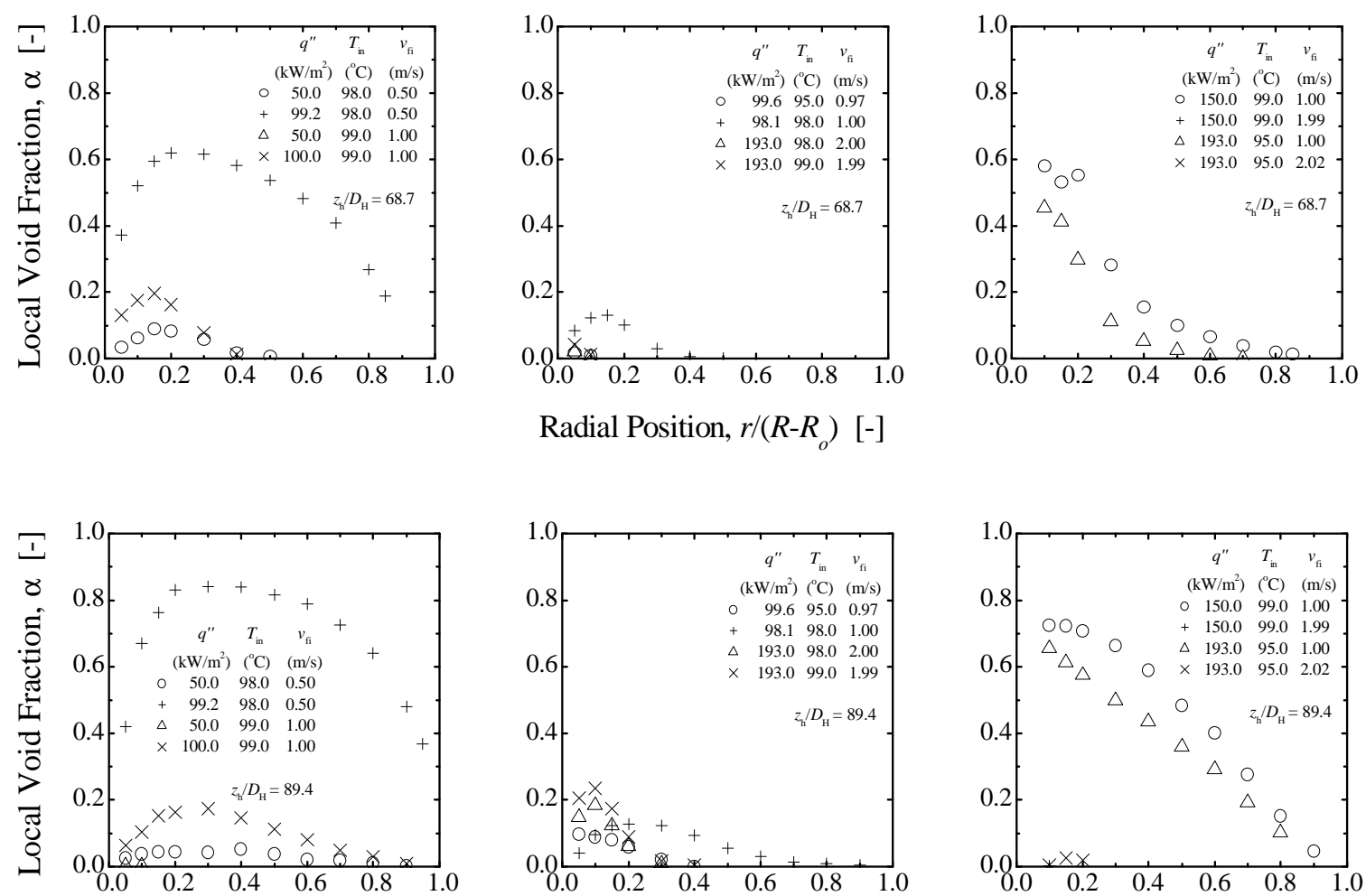

Radial Position, $r /\left(R-R_{o}\right) \quad[-]$ 
Fig. 4
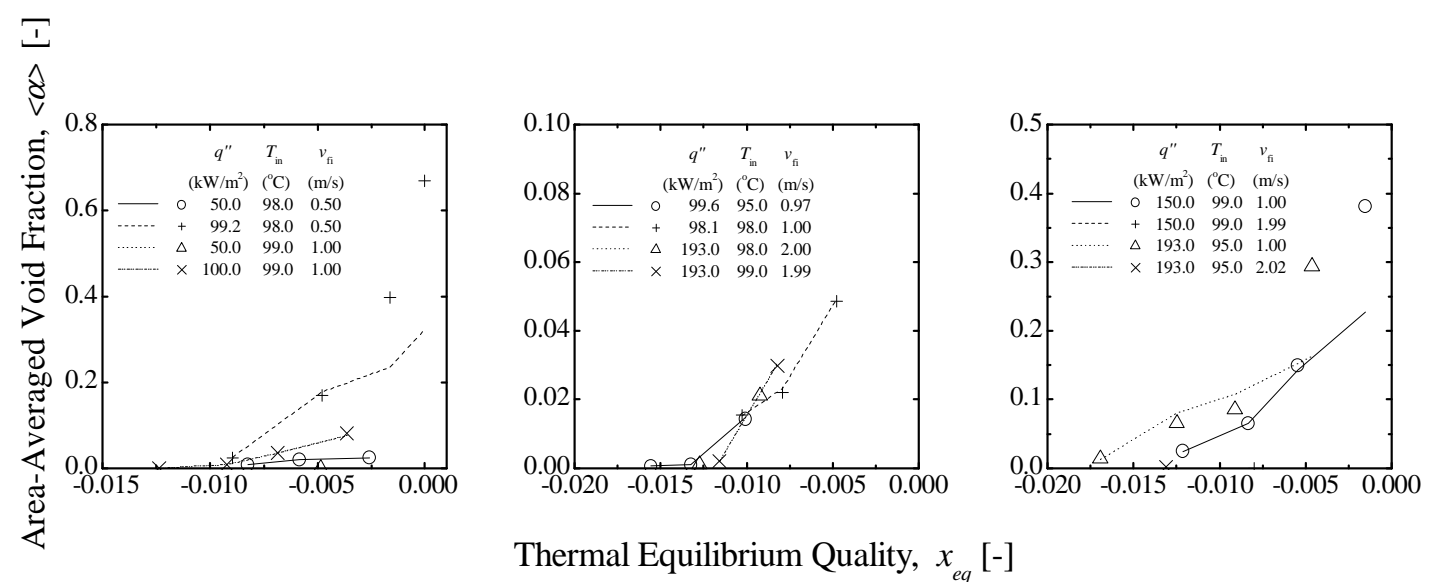

Thermal Equilibrium Quality, $x_{e q}[-]$ 
Fig. 5

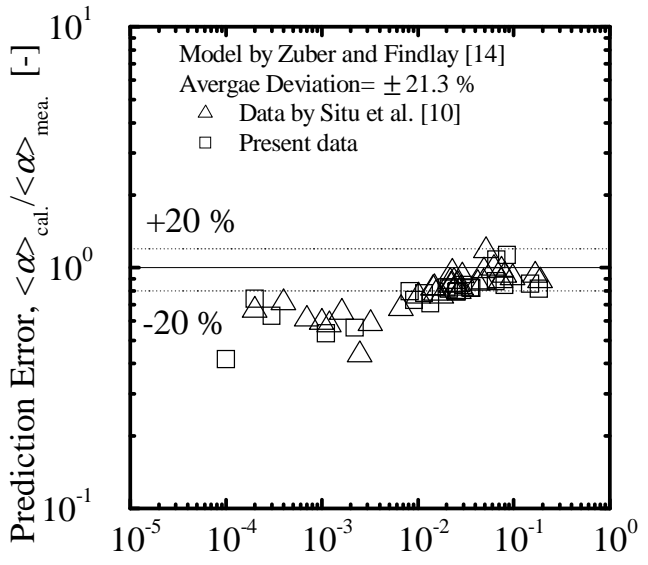

Area-Averaged Void Fraction, $\langle\alpha\rangle[-]$

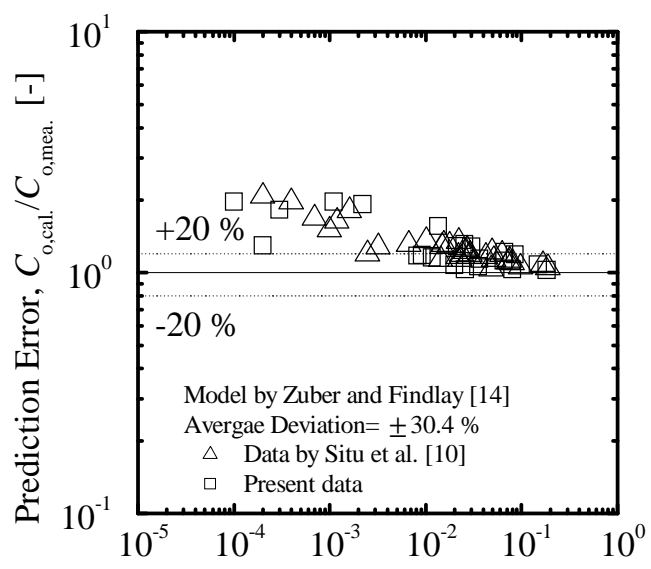

Area-Averaged Void Fraction, $\langle\alpha\rangle[-]$

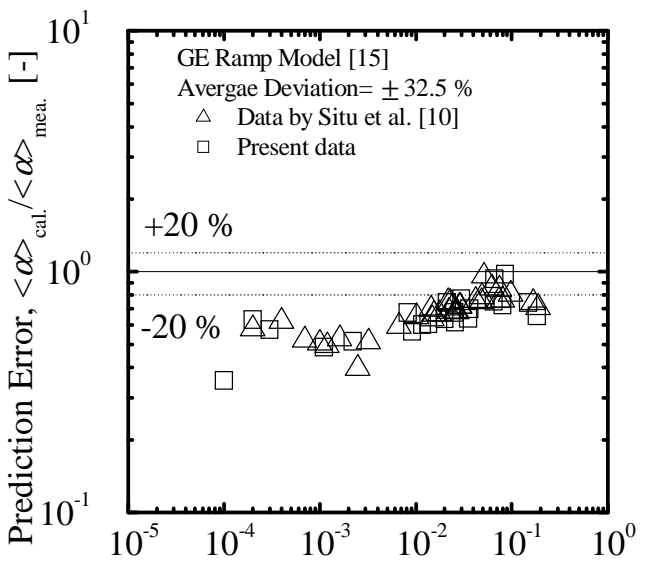

Area-Averaged Void Fraction, $\langle\alpha\rangle$ [-]

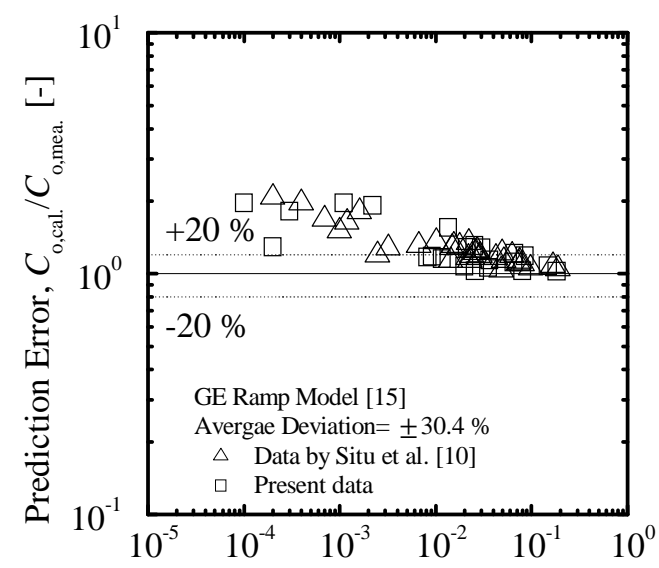

Area-Averaged Void Fraction, $\langle\alpha\rangle$ [-]

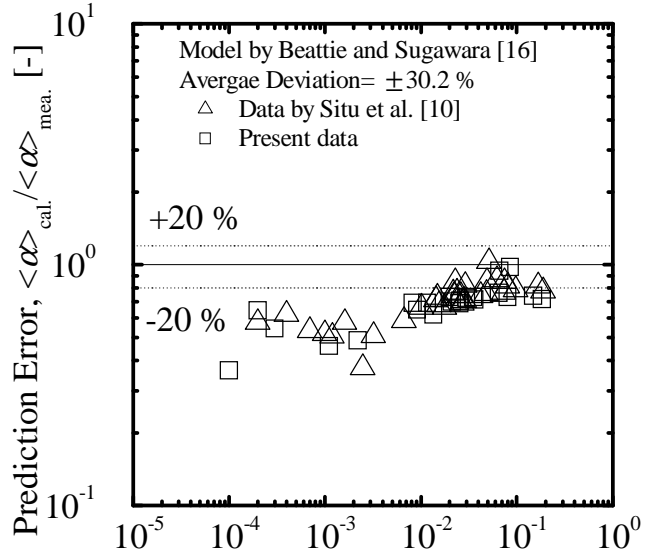

Area-Averaged Void Fraction, $\langle\alpha\rangle[-]$

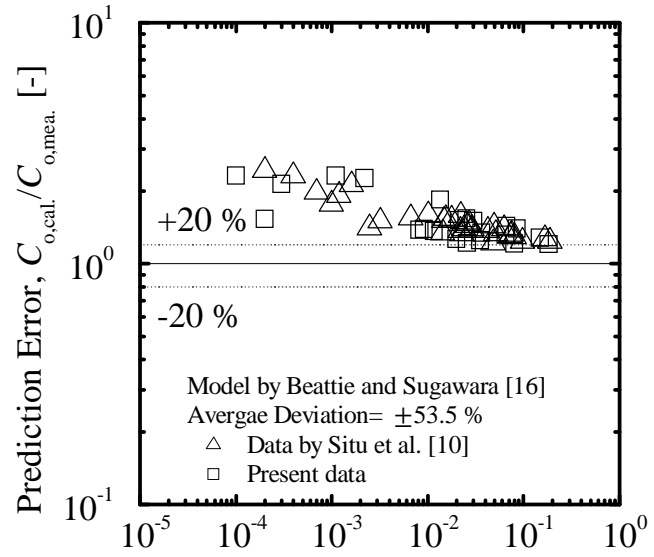

Area-Averaged Void Fraction, $\langle\alpha\rangle[-]$ 


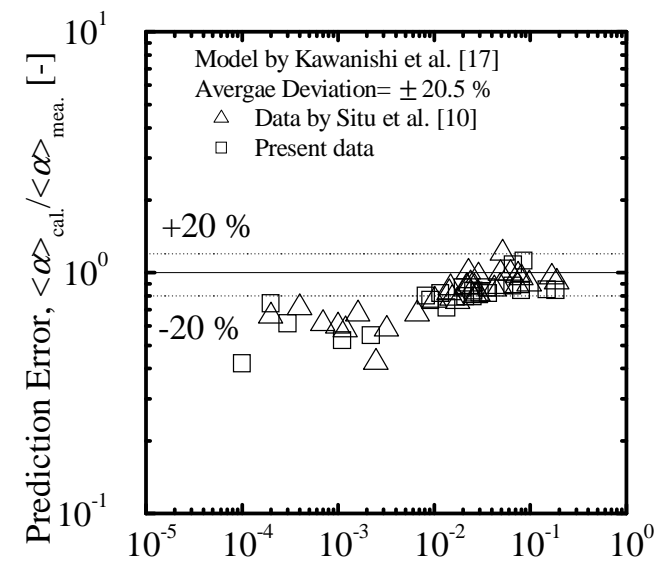

Area-Averaged Void Fraction, $\langle\alpha\rangle[-]$

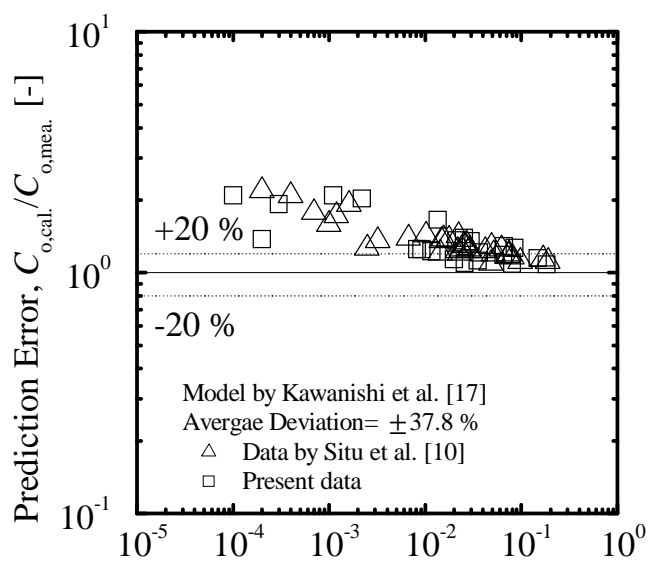

Area-Averaged Void Fraction, $\langle\alpha\rangle[-]$

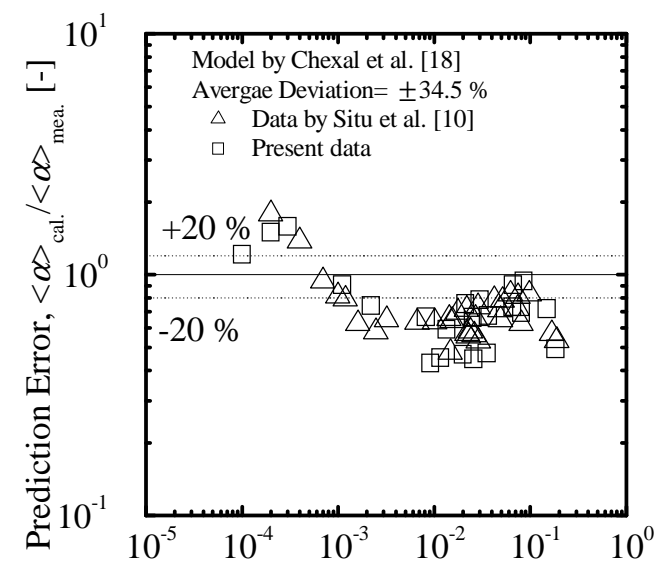

Area-Averaged Void Fraction, $\langle\alpha\rangle$ [-]

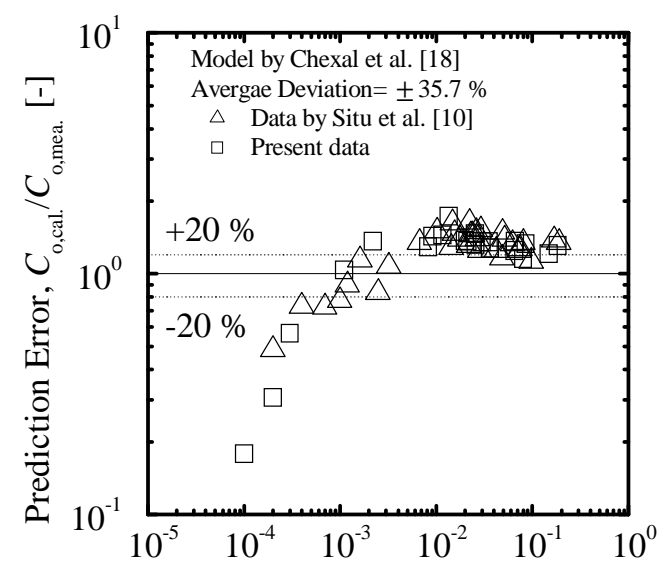

Area-Averaged Void Fraction, $\langle\alpha\rangle[-]$

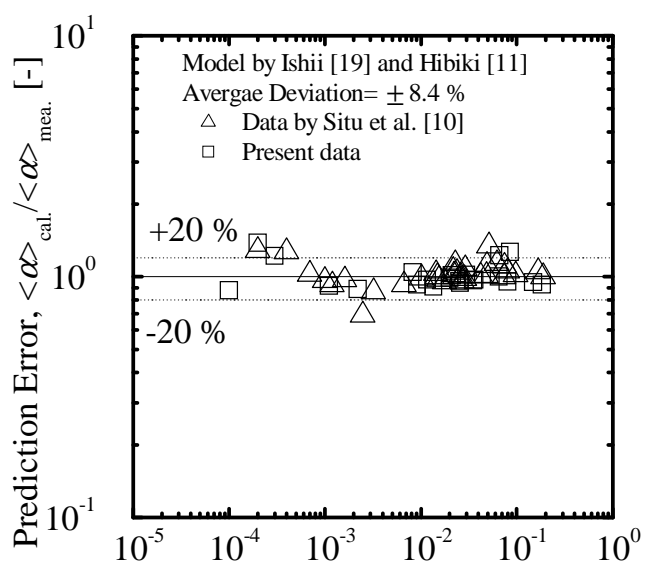

Area-Averaged Void Fraction, $\langle\alpha\rangle[-]$

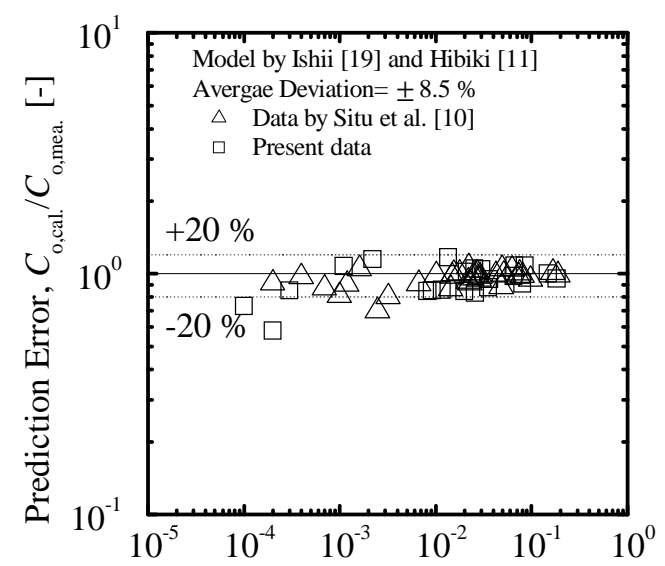

Area-Averaged Void Fraction, $\langle\alpha\rangle[-]$ 
Fig. 6
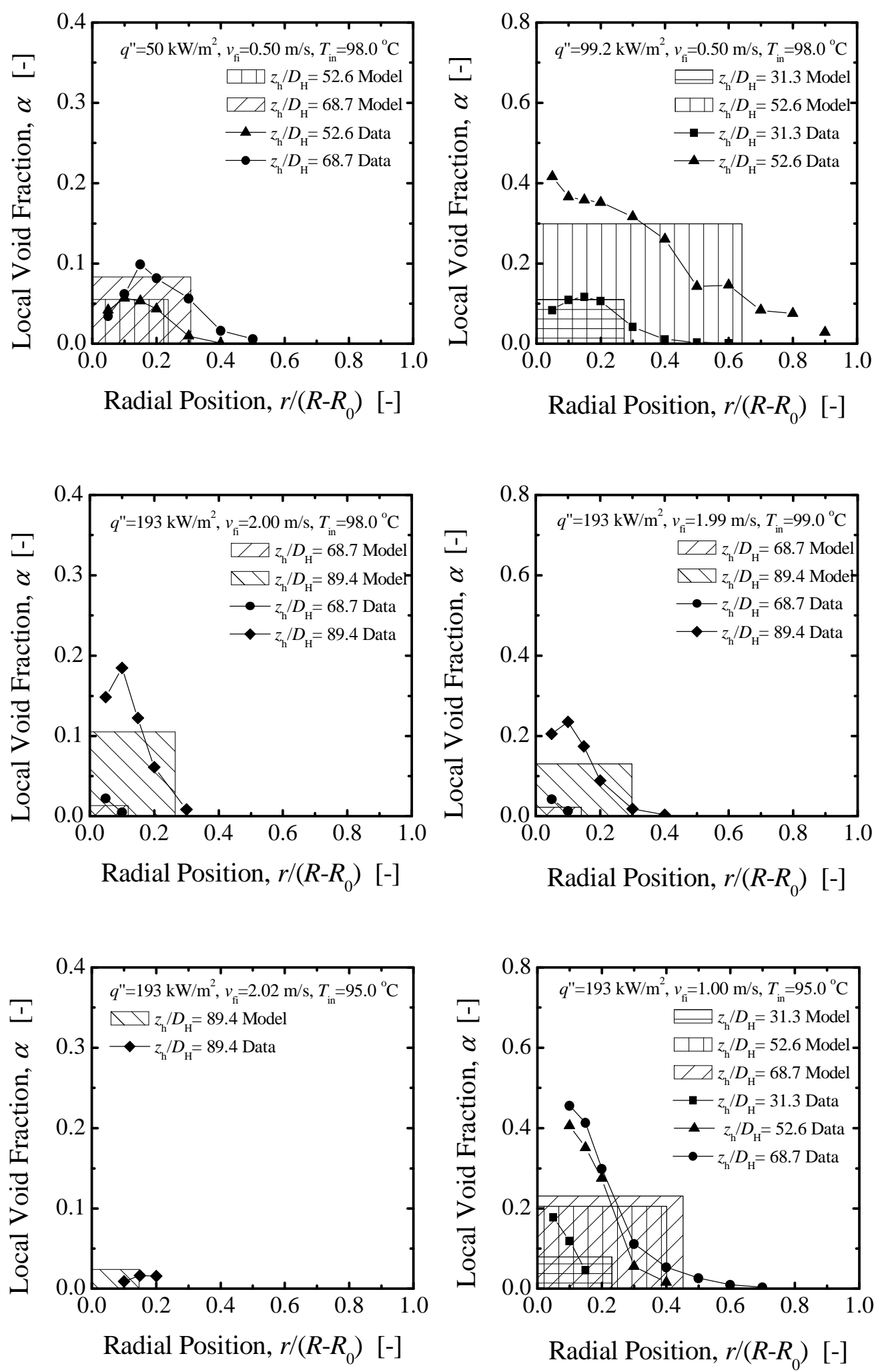
Fig. 7
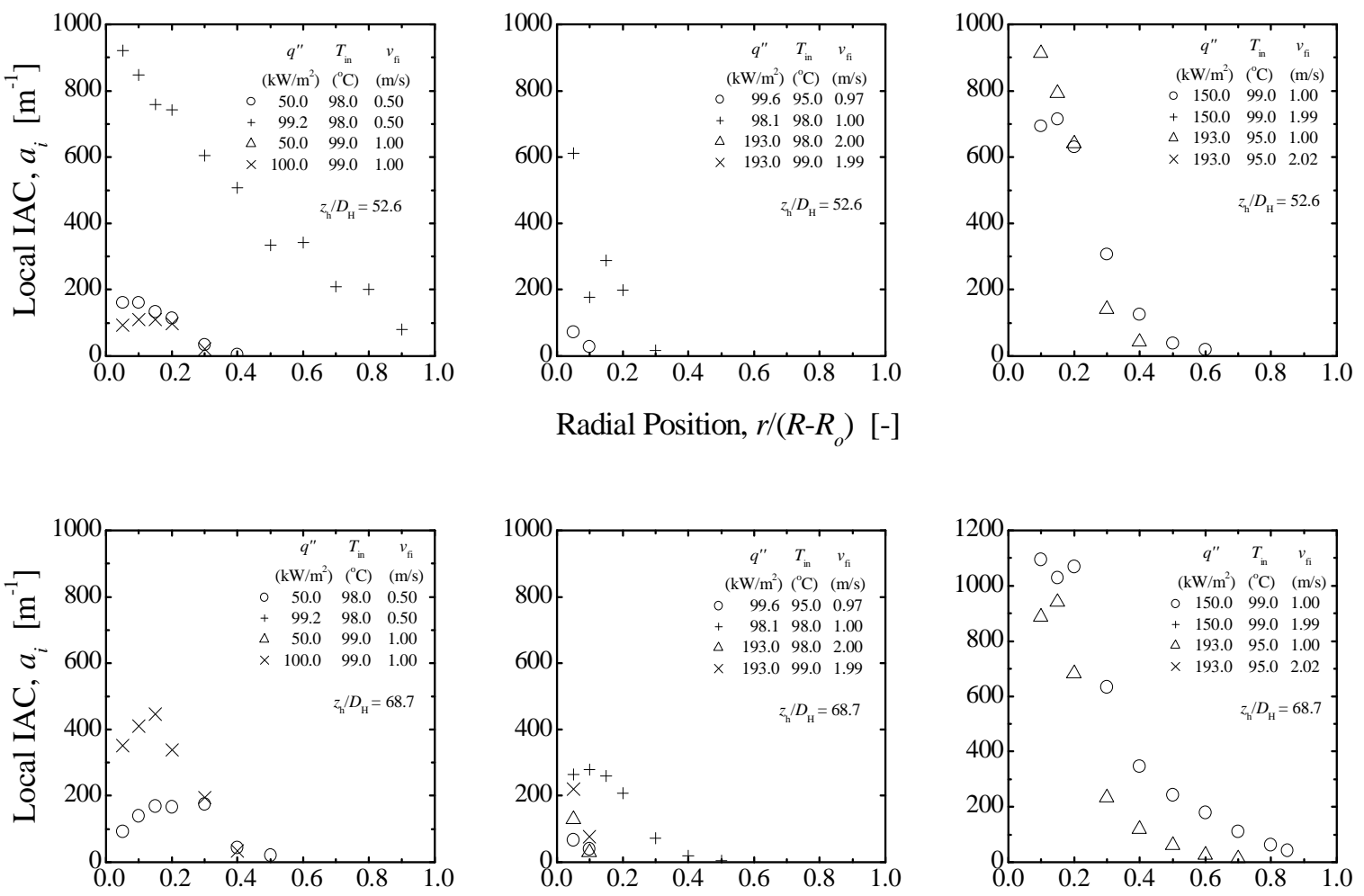

Radial Position, $r /\left(R-R_{o}\right)[-]$
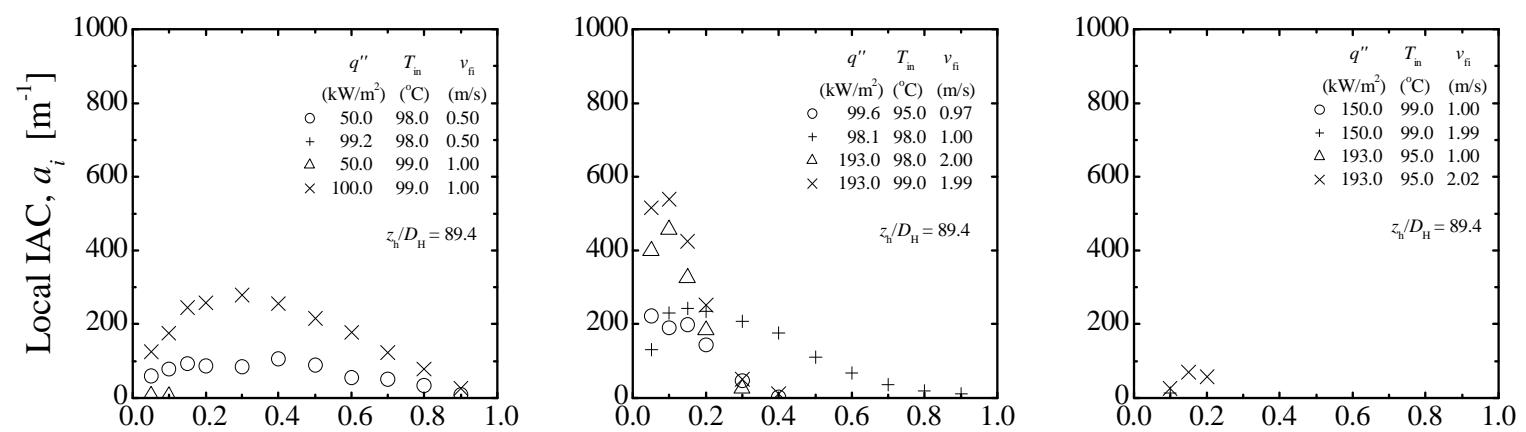

Radial Position, $r /\left(R-R_{o}\right)[-]$ 
Fig. 8
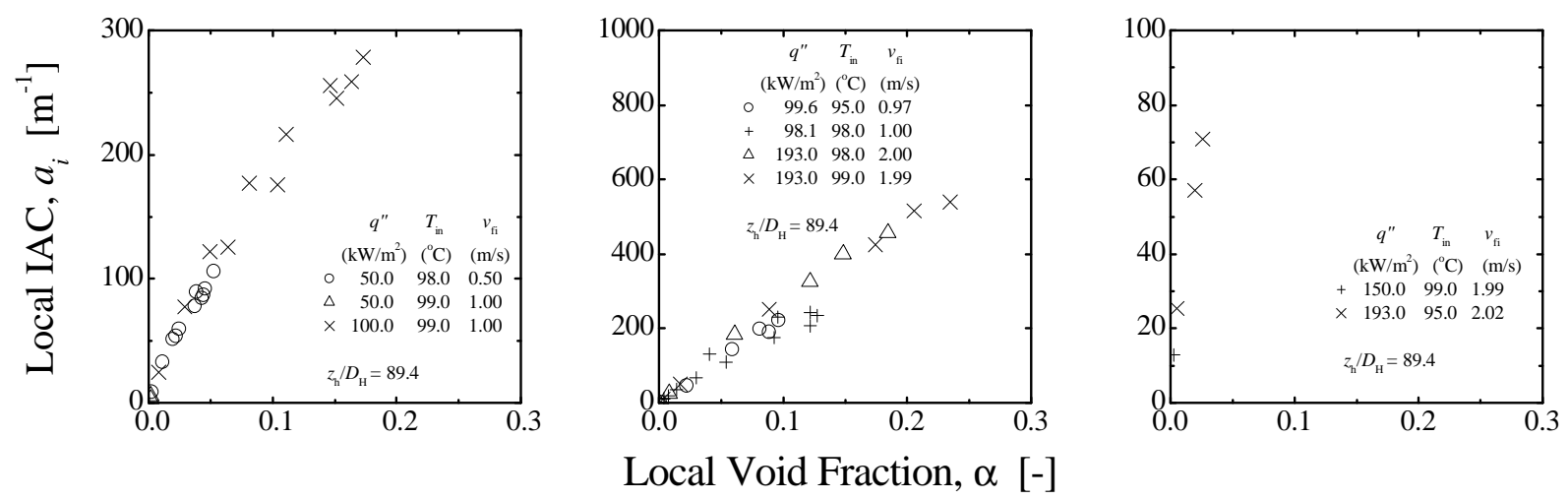
Fig. 9
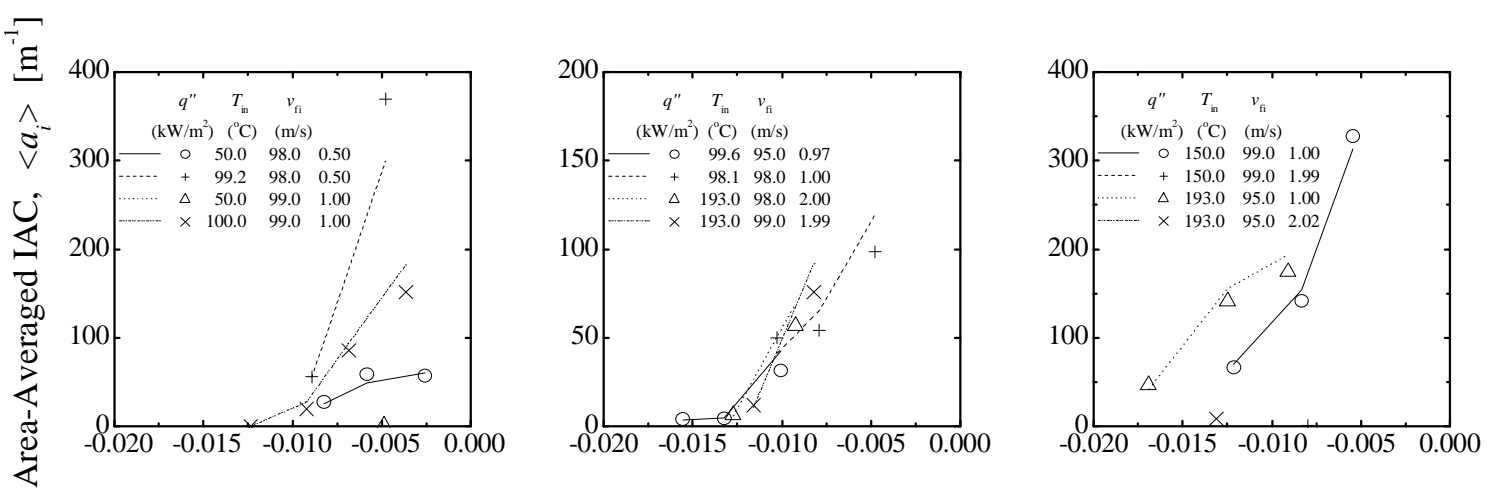

Thermal Equilibrium Quality, $x_{e q}[-]$ 
Fig. 10

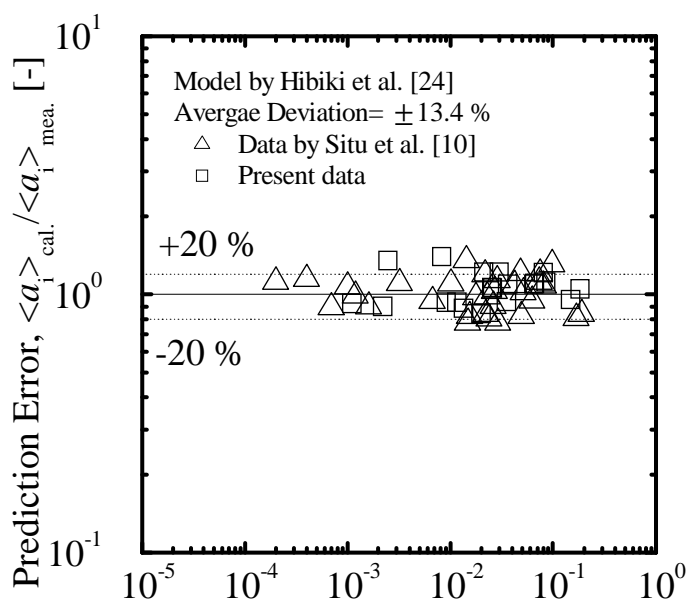

Area-Averaged Void Fraction, $\langle\alpha\rangle[-]$

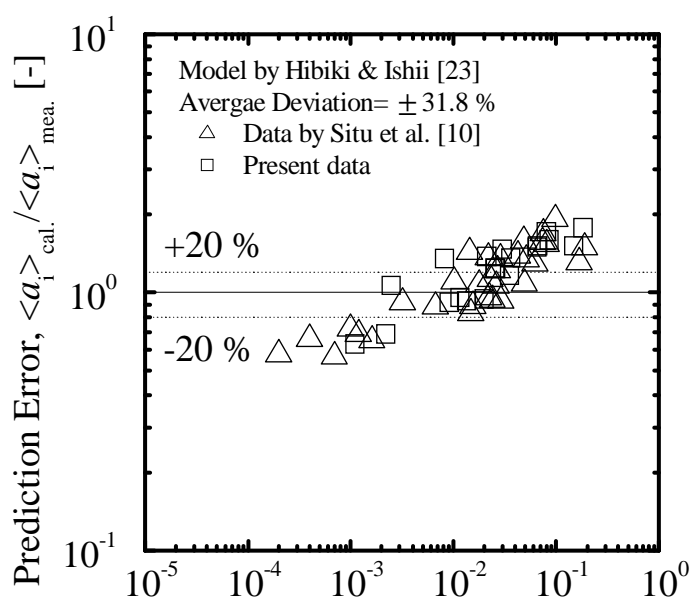

Area-Averaged Void Fraction, $<\alpha>[-]$

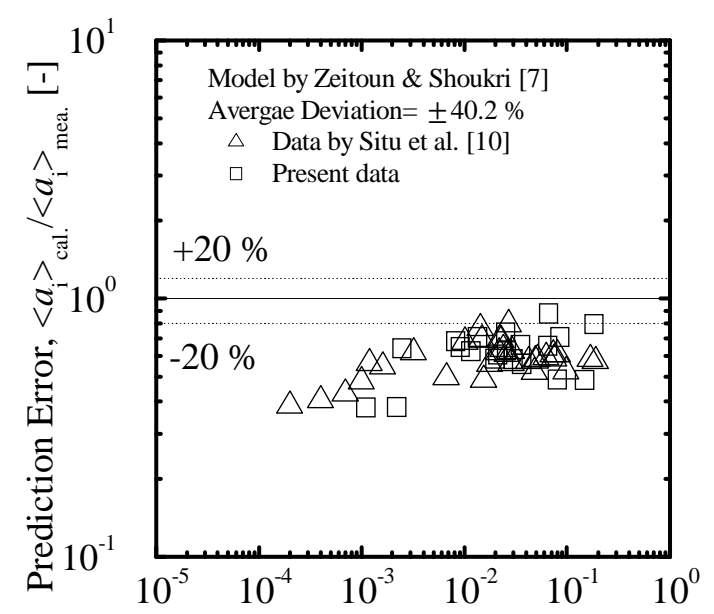

Area-Averaged Void Fraction, $\langle\alpha\rangle[-]$

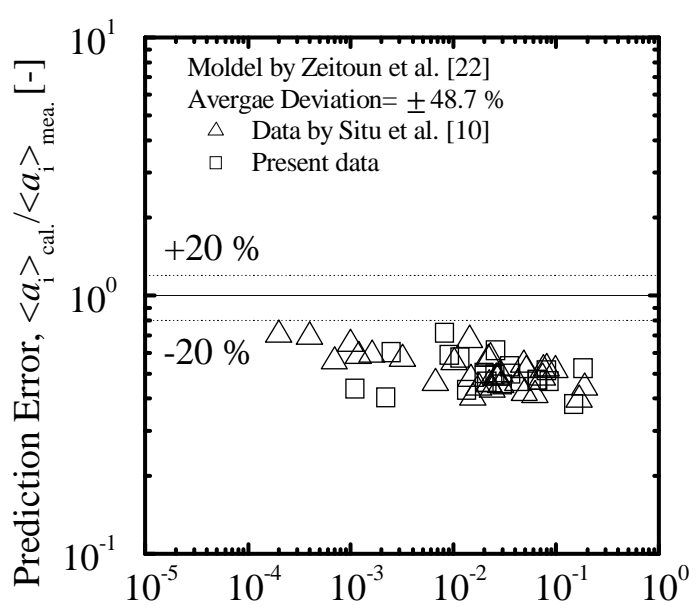

Area-Averaged Void Fraction, $\langle\alpha\rangle[-]$ 
Fig. 11
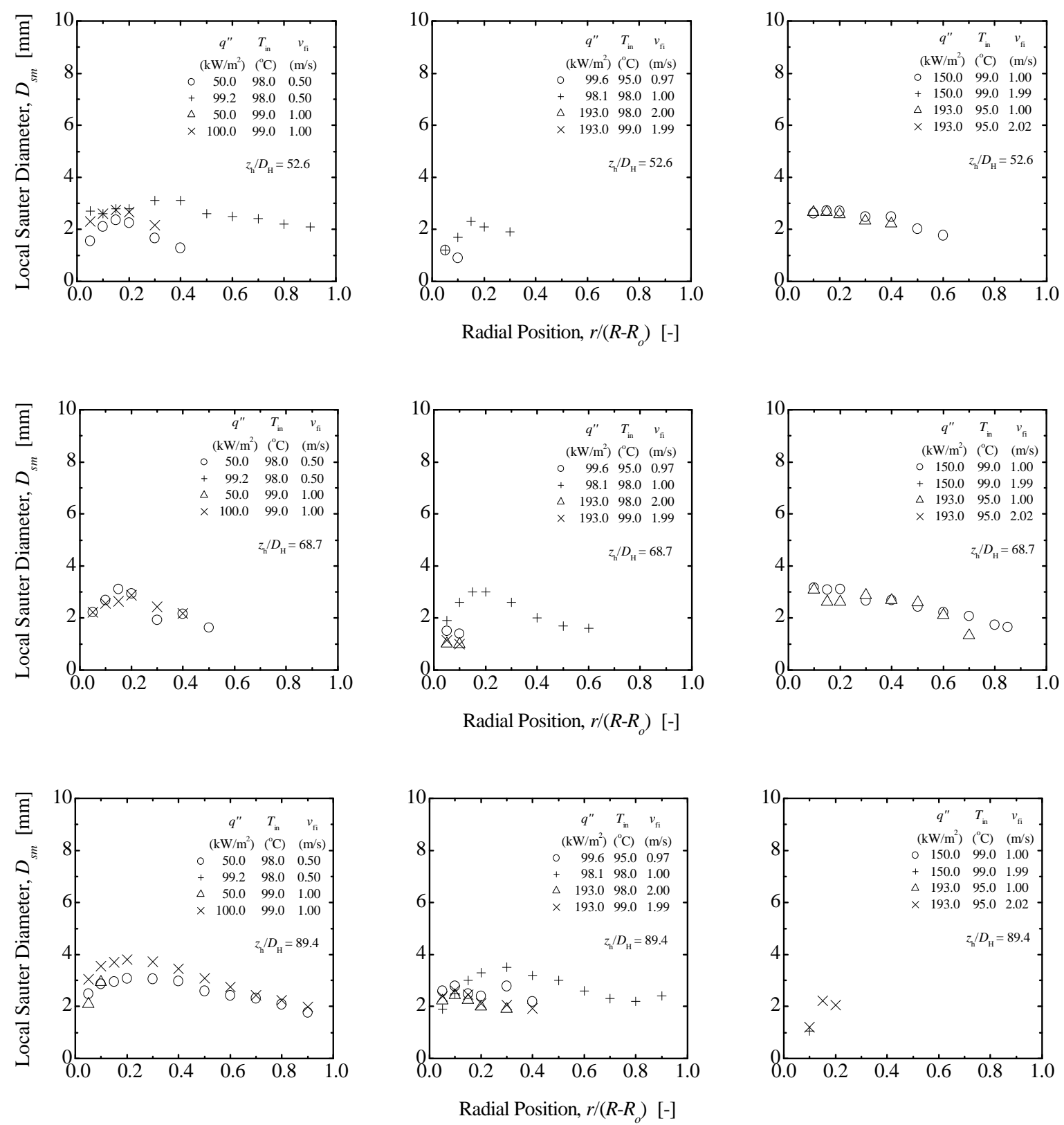